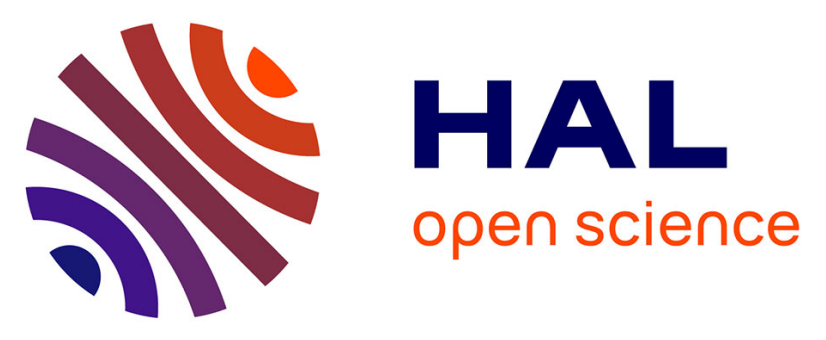

\title{
The Spectral Nature of Titan's Major Geomorphological Units: Constraints on Surface Composition
}

\author{
Anezina Solomonidou, Athena Coustenis, Rosaly M. C. Lopes, Michael J. \\ Malaska, Sébastien Rodriguez, Pierre Drossart, Charles Elachi, Bernard \\ Schmitt, Sylvain Philippe, Michael Janssen, et al.
}

\section{To cite this version:}

Anezina Solomonidou, Athena Coustenis, Rosaly M. C. Lopes, Michael J. Malaska, Sébastien Rodriguez, et al.. The Spectral Nature of Titan's Major Geomorphological Units: Constraints on Surface Composition. Journal of Geophysical Research. Planets, 2018, 123 (2), pp.489-507. 10.1002/2017JE005477 . insu-01696077

\section{HAL Id: insu-01696077 https://hal-insu.archives-ouvertes.fr/insu-01696077}

Submitted on 6 Aug 2020

HAL is a multi-disciplinary open access archive for the deposit and dissemination of scientific research documents, whether they are published or not. The documents may come from teaching and research institutions in France or abroad, or from public or private research centers.
L'archive ouverte pluridisciplinaire HAL, est destinée au dépôt et à la diffusion de documents scientifiques de niveau recherche, publiés ou non, émanant des établissements d'enseignement et de recherche français ou étrangers, des laboratoires publics ou privés. 


\section{Journal of Geophysical Research: Planets}

\section{RESEARCH ARTICLE \\ 10.1002/2017JE005477 \\ The Spectral Nature of Titan's Major Geomorphological Units: Constraints on Surface Composition}

Key Points:

- The spectral nature of some of Titan's major geomorphological units at midlatitudes is described using a radiative transfer code

- Three main categories of albedo govern Titan's low-midlatitude surface regions, and its surface composition has a latitudinal dependence

- The surface albedo differences and similarities among the Rols set constraints on possible formation and/or evolution processes

Correspondence to:

A. Solomonidou,

anezina.solomonidou@esa.int

\section{Citation:}

Solomonidou, A., Coustenis, A., Lopes, R. M. C., Malaska, M. J., Rodriguez, S., Drossart, P., et al. (2018). The spectral nature of Titans major geomorphological units: Constraints on surface composition. Journal of Geophysical Research: Planets, 123, 489-507. https:// doi.org/10.1002/2017JE005477

Received 2 NOV 2017

Accepted 25 JAN 2018

Accepted article online 29 JAN 2018

Published online 22 FEB 2018

(C)2018. American Geophysical Union. All Rights Reserved.

\author{
A. Solomonidou ${ }^{1,2,3}$ (D) A. Coustenis ${ }^{3}$, R. M. C. Lopes ${ }^{4}$ (D) M. J. Malaska ${ }^{4}$ (D, S. Rodriguez ${ }^{5}$, \\ P. Drossart ${ }^{3}$ D , C. Elachi ${ }^{1}$, B. Schmitt ${ }^{6}$ D , S. Philippe ${ }^{6}$, M. Janssen ${ }^{4}$ D, M. Hirtzig ${ }^{7}$, S. Wall ${ }^{4}$, C. Sotin ${ }^{4}$, \\ K. Lawrence ${ }^{4}$, N. Altobelli ${ }^{2}$, E. Bratsolis ${ }^{8}$, J. Radebaugh ${ }^{9}$, K. Stephan ${ }^{10}$ (D), R. H. Brown ${ }^{11}$, S. Le Mouélic ${ }^{12}$, \\ A. Le Gall ${ }^{13}$, E. V. Villanueva ${ }^{4}$, J. F. Brossier ${ }^{10}$ iD, A. A. Bloom ${ }^{4}$ D, O. Witasse ${ }^{14}$ iD, C. Matsoukas ${ }^{15}$, and \\ A. Schoenfeld ${ }^{16}$
}

${ }^{1}$ California Institute of Technology, Pasadena, CA, USA, ${ }^{2}$ European Space Astronomy Centre, European Space Agency, Madrid, Spain, ${ }^{3}$ LESIA-Observatoire de Paris, Paris Sciences and Letters Research University, CNRS, Sorbonne Université, Université Paris-Diderot, Meudon, France, ${ }^{4}$ Jet Propulsion Laboratory, California Institute of Technology, Pasadena, CA, USA, Institut de Physique du Globe de Paris, CNRS-UMR 7154, Université Paris-Diderot, USPC, Paris, France, ' Institut de Planétologie et d'Astrophysique de Grenoble, Université Grenoble Alpes, CNRS, Grenoble, France, ${ }^{7}$ Fondation "La main à la pâte", Montrouge, France, ${ }^{8}$ Department of Physics, University of Athens, Athens, Greece, ${ }^{9}$ Department of Geological Sciences, Brigham Young University, Provo, UT, USA, ${ }^{10}$ Institute of Planetary Research, DLR, Berlin, Germany, ${ }^{11}$ Lunar and Planetary Laboratory, University of Arizona, Tucson, AZ, USA, ${ }^{12}$ Laboratoire de Planétologie et Géodynamique, CNRS UMR 6112, Université de Nantes, Nantes, France, ${ }^{13}$ LATMOS/IPSL, UPMC Université Paris 6, Sorbonne Universités, UVSQ, CNRS, Paris, France, ${ }^{14}$ European Space Research and Technology Centre, European Space Agency, Noordwijk, Netherlands, ${ }^{15} \mathrm{KTH}$-Royal Institute of Technology, Stockholm, Sweden, ${ }^{16}$ Department of Earth, Planetary, and Space Sciences, University of Calilfornia, Los Angeles, CA, USA

Abstract We investigate Titan's low-latitude and midlatitude surface using spectro-imaging near-infrared data from Cassini/Visual and Infrared Mapping Spectrometer. We use a radiative transfer code to first evaluate atmospheric contributions and then extract the haze and the surface albedo values of major geomorphological units identified in Cassini Synthetic Aperture Radar data, which exhibit quite similar spectral response to the Visual and Infrared Mapping Spectrometer data. We have identified three main categories of albedo values and spectral shapes, indicating significant differences in the composition among the various areas. We compare with linear mixtures of three components (water ice, tholin-like, and a dark material) at different grain sizes. Due to the limited spectral information available, we use a simplified model, with which we find that each albedo category of regions of interest can be approximately fitted with simulations composed essentially by one of the three surface candidates. Our fits of the data are overall successful, except in some cases at $0.94,2.03$, and $2.79 \mu \mathrm{m}$, indicative of the limitations of our simplistic compositional model and the need for additional components to reproduce Titan's complex surface. Our results show a latitudinal dependence of Titan's surface composition, with water ice being the major constituent at latitudes beyond $30^{\circ} \mathrm{N}$ and $30^{\circ} \mathrm{S}$, while Titan's equatorial region appears to be dominated partly by a tholin-like or by a very dark unknown material. The albedo differences and similarities among the various geomorphological units give insights on the geological processes affecting Titan's surface and, by implication, its interior. We discuss our results in terms of origin and evolution theories.

Plain Language Summary Titan, Saturn's moon, has been investigated by the Cassini mission for almost 13 years, unveiling an exotic world with many features similar to Earth. One of the mysteries that still has not been resolved even after that many years of exploration is the nature of its surface composition. Titan is a very complex world with multivariable geology and a very thick and hazy atmosphere that shields the surface from remote sensing observations, prohibiting direct evaluation of its composition. In our study we analyze spectro-imaging data from the Cassini visual and infrared spectrometer. We first infer the atmospheric contribution and then extract true surface properties. We study major geomorphological regions on Titan, which include among other mountains, plains, craters, and dunes. We derive their surface albedo values and shapes that reveal the brightness of the surface and compare them with materials that we expect to find on Titan's surface, such as water ice, tholins (atmospheric products), and a very dark unknown component. The results from this analysis show that Titan presents a pattern in its surface composition distribution with its equator being dominated by organic materials from the atmosphere and a very dark unknown material, while higher latitudes contain more water ice. 


\section{Context and Observations}

In order to constrain the geologic history of Titan, it is important to determine the morphology and composition of the different geomorphological units (i.e., surface terrains with various geological characteristics) that may indicate surficial activity and/or deposits. Due to Titan's extended, dense, and hazy methane-laden atmosphere, direct observation of the surface is only possible using radar, and spectroscopic imaging at a few specific frequencies in the near-infrared, where the methane absorption is weak (Sotin et al., 2005; Tomasko et al., 2005). The presence of methane is at the heart of several atmospheric and surface processes that forge the satellite's surface morphology and composition. One of the mysteries in Titan's studies is that, given the preservation limit of methane of 10-30 Myr (Atreya, 2010), subsurface reservoir(s) and mechanisms for resupplying the atmosphere are required but remain to be identified (Sohl et al., 2014; Tobie et al., 2006). If the source is located in the interior of the satellite, then possible mechanisms to bring it to the atmosphere through the surface have been proposed, including cryovolcanism (e.g., Lopes et al., 2007, 2013; Tobie et al., 2006), methane evaporation from the lakes (Mitri et al., 2007), and exchange with a clathrate reservoir (Choukroun \& Sotin, 2012). Thus, the atmosphere, surface, and interior are interlinked, and in order to understand the origin and evolution of Titan, it is necessary to study its surface geology as it can bring new insights into the nature of the interior-surface-atmosphere exchanges.

We use data from two Cassini spacecraft instruments: the Visual and Infrared Mapping Spectrometer (VIMS) and the Titan Radar Mapper (RADAR) in its Synthetic Aperture Radar (SAR) mode (Brown et al., 2004; Elachi et al., 2004). We use data acquired during the 2004-2014 period and apply new analysis techniques, such as data superposition and updated radiative transfer (RT) analysis, in order to optimize the extracted information. During this period of time, VIMS obtained spectro-imaging data of Titan's surface and lower atmosphere in the 0.89-5.2 $\mu \mathrm{m}$ range during 98 Cassini flybys of Titan. The surface contribution to the VIMS recorded spectra was obtained in seven atmospheric spectral "windows" where the methane absorption is weak, centered at $0.94,1.08,1.28,1.59,2.03,2.69-2.79$, and $5 \mu \mathrm{m}$. In our analysis, the atmospheric scattering and absorption are evaluated prior to extracting the contribution from the surface. Hirtzig et al. (2013) and Solomonidou et al. $(2014,2016)$ describe the details of the method and the model applied here, but a brief description is also provided in section 2. As in our previous studies, the selection of regions of interest (Rols) included in this study is based on the scientific significance that a region or feature offers and the availability of VIMS data compatible with our RT plane-parallel geometry.

RADAR data were also used in this study. The RADAR instrument operates at a frequency of $13.78 \mathrm{GHz}(2.2 \mathrm{~cm}$ wavelength, Ku-band) and in four modes: SAR, altimetry, scatterometry, and radiometry. The SAR mode provides images at resolutions of $\sim 300 \mathrm{~m}$ to $1.5 \mathrm{~km}$ (Elachi et al., 2004). The backscatter intensity of the SAR images is governed by the slope, roughness, volume scattering, and composition of the surface (Janssen et al., 2011). We use the SAR data to accurately select the VIMS pixels that correspond to the areas of geologic interest.

Previous studies have identified several major surface units on Titan. In early studies from VIMS data, the major spectral units identified from color composites (red, green, and blue-RGB) were the so-called "bright" units that were found to generally correspond to mountains and elevated areas in radar, the "brown" units that were found to correspond to dune materials (Rodriguez et al., 2014), and the "blue" units found at boundary (dark-bright) areas (Barnes et al., 2007; Jaumann et al., 2009; Le Mouélic et al., 2008; Soderblom, Tomasko, et al., 2007). Lopes et al. (2010) used RADAR data to distinguish three major geologic units on Titan's globe: (i) geomorphologic units (cryovolcanic, hummocky/mountainous, and impact craters), (ii) surficial units (dunes, fluvial channels, and lakes), and (iii) units of uncertain origin (crateriform structures and plains such as undifferentiated and mottled). More recently, detailed geomorphological mapping using SAR data by Lopes et al. (2016) and Malaska et al. (2016) described terrains in six broad classes: labyrinth units, crater units, hummocky/mountainous units, plain units, dune units, and lakes. In turn, these classes are composed of additional units. For example, several plain units exist, such as undifferentiated, streak-like, variable-featured, and scalloped terrains (i.e., irregular medium-bright patches of lobate to cuspate morphology) (see Table 1 for more descriptions). Even though some suggestions have been put forward about the surface composition of Titan by a number of studies (e.g., water ice, Coustenis et al., 1995; Griffith et al., 2003; McCord et al., 2006; carbon dioxide, Hartung et al., 2006; McCord et al., 2008; trace detection of solid and liquid hydrocarbons, Clark et al., 2010; and acetylene ice, Singh et al., 2016), the precise chemical composition of the different geomorphological units on Titan's surface has not been defined to date. 
Table 1

Various Surface Units

\begin{tabular}{|c|c|c|}
\hline Geomorphological unit & Description & References \\
\hline Undifferentiated plains ( $p u l$ ) & $\begin{array}{l}\text { Low-backscatter regions with very few features } \\
\text { present on SAR images }\end{array}$ & Lopes et al. $(2010,2016) ;$ Malaska et al. (2016) \\
\hline Variable plains ( $p f v$ ) & $\begin{array}{l}\text { Diverse units that range from medium- to low-backscatter } \\
\text { regions and consist of various internal textures }\end{array}$ & Malaska et al. (2016) \\
\hline Streak-like plains ( $p s h)$ & $\begin{array}{l}\text { Diffuse- textured high-backscatter elongated regions with sharp to diffuse } \\
\text { extended linear to curvilinear boundaries }\end{array}$ & Malaska et al. (2016) \\
\hline Scalloped plains (psv) & $\begin{array}{l}\text { Unit composed of irregular medium-bright patches of lobate to cuspate } \\
\text { morphology set in low- to medium-backscatter terrain. }\end{array}$ & Malaska et al. (2016) \\
\hline Hummocky terrains $(h h) /$ & $\begin{array}{l}\text { High-backscatter regions with isolated patches of radar-bright } \\
\text { material (hummocky) and radar-bright mountain chains (mountains) }\end{array}$ & $\begin{array}{l}\text { Radebaugh et al. (2007); Lopes et al. (2010); } \\
\text { Malaska et al. (2016) }\end{array}$ \\
\hline Labyrinth terrains $(\mathrm{lb})$ & Locally high-backscatter units and largely dissected features & Malaska et al. (2016) \\
\hline Dunes $(d l)$ & $\begin{array}{l}\text { Featureless sand sheets with lower backscatter } \\
\text { than the undifferentiated plain units }\end{array}$ & $\begin{array}{l}\text { Radebaugh et al. (2008); Lopes et al. (2010); Le Gall } \\
\text { et al. (2014); Mastroguiseppe et al. (2014); } \\
\text { Rodriguez et al. (2014) }\end{array}$ \\
\hline Crater ejecta (ceh) & $\begin{array}{l}\text { Rough-, high-, to medium-backscatter terrains that grade } \\
\text { radially outward from an impact crater rim unit }\end{array}$ & $\begin{array}{l}\text { Lorenz et al. (2007); Wood et al. (2010); Malaska et al. } \\
\text { (2016); Neish et al. (2016) }\end{array}$ \\
\hline Alluvial fans (af) & Fan-shaped mass of alluvium deposits & Lorenz et al. (2008); Radebaugh et al. (2016) \\
\hline
\end{tabular}

Note. Terrain unit code for the geomorphological units from Malaska et al. (2016); we added a codename (af) for the alluvial fans.

Here we focus on constraining the compositions of the surface units at low-latitude and midlatitude from $60^{\circ} \mathrm{S}$ to $60^{\circ} \mathrm{N}$ as described in Table 1. The geomorphologic units are hummocky/mountainous (hh) and labyrinth $(l b)$ terrains; the undifferentiated (pul), variable (pfv), the scalloped (psv), and streak-like plains (psh); the dunes $(d s)$; the alluvial fans $(a f)$; and the crater ejecta units (ceh). The different surface units we examine here are described in Table 1. Their various precise locations within the midlatitudes are summarized in Table 2 and shown in Figure 1.

Furthermore, we use the Huygens landing site (HLS) as a reference area, providing ground truth. Our HLS pixel selection is part of a VIMS datacube with $15 \mathrm{~km}$ resolution. The HLS is a dune-free region with bright and dark features as identified on Descent Imager/Spectral Radiometer (DISR) and VIMS images (e.g., Rodriguez et al., 2006; Soderblom, Tomasko, et al., 2007; Soderblom, Kirk, et al., 2007).

Lopes et al. (2016), using Cassini/RADAR data, showed that the undifferentiated plain units cover $\sim 17 \%$ of Titan's mapped surface, confirming the conclusion by Lopes et al. (2010) that the undifferentiated plains are the most widespread unit on Titan. The second most common unit on Titan-as seen by Cassini's SAR-is the dune unit, with estimated coverage ranging from 14 to 18\% (Le Corre et al., 2008). Hummocky/mountainous terrains are also widespread on Titan, covering $\sim 13 \%$ of the surface (Lopes et al., 2016). Other units mapped by Lopes et al. $(2010,2016)$ were significantly smaller in area; for example, labyrinth terrains cover $\sim 3 \%$ of the total mapped surface.

In this paper, we investigate two regions of undifferentiated plains, following the work in Lopes et al. (2016), who found differences in the VIMS-determined albedos between plains in Caladan Planitia (close to equator) and undifferentiated plains located further away from the equator. The albedos of the Caladan Planitia Rols showed a spectral shape similar to that found in the other undifferentiated plains, but with much lower surface albedo values, which we interpreted as due to dune material contamination. Therefore, here we group together the plains located at higher latitudes (those close to the NE Soi crater, those at Poritrin Planitia, and those close to Richese labyrinth) and call them "undifferentiated plains 1." The undifferentiated plains located closer to the equator in the Caladan Planitia area are referred to as "undifferentiated plains 2" (Table 2 and Figure 1).

In Solomonidou et al. (2014) and Hirtzig et al. (2013) we attempted to constrain spectroscopic properties for a small number of Titan regions by performing comparisons between retrieved albedos for these regions and laboratory reflectance spectra of some possible pure chemical candidates for Titan's surface composition. In addition, we provided implications for the undifferentiated plains' (pul1 and pul2) possible composition in Lopes et al. (2016), where we proposed tholin-like material to be the major constituent. Furthermore, the 
Table 2

Names of Geomorphological Units and Target Regions, Related Flybys ("T"Stands for Cassini Flybys of Titan) and Dates for VIMS and SAR Swaths of the Study Regions, and Center of Coordinates for the Regions of Interest, Angles of Incidence (i), Emission (e), Phase ( $\alpha$ ), and Spatial Resolution (res) of the VIMS Cubes

\begin{tabular}{|c|c|c|c|c|}
\hline Name & Date (Flyby) for VIMS & Date (Flyby) for RADAR & Centroid Coordinates & VIMS $i / e / \alpha / \operatorname{Res}$ \\
\hline \multicolumn{5}{|l|}{ Undifferentiated plains 1 (pul1) } \\
\hline NE Soi & 10/2005 (T8) & 5/2009 (T55) & $30.4^{\circ} \mathrm{N}, 133.3^{\circ} \mathrm{W}$ & $51^{\circ} / 34^{\circ} / 23^{\circ} / 75 \mathrm{~km}$ \\
\hline Poritrin Planitia & 8/2005 (T6) & 6/2010 (T69) & $50^{\circ} \mathrm{N}, 41.9^{\circ} \mathrm{W}$ & $60^{\circ} / 40^{\circ} / 52^{\circ} / 42 \mathrm{~km}$ \\
\hline Near Richese & 6/2010 (T70) & 5/2012 (T83) & $43.5^{\circ} \mathrm{N}, 203^{\circ} \mathrm{W}$ & $49^{\circ} / 51^{\circ} / 32^{\circ} / 17 \mathrm{~km}$ \\
\hline \multicolumn{5}{|l|}{ Undifferentiated plains 2 (pul2) } \\
\hline Caladan Planitia 1 & 2/2011 (T74) & 6/2012 (T84) & $17.5^{\circ} \mathrm{N}, 216.5^{\circ} \mathrm{W}$ & $27^{\circ} / 22^{\circ} / 33^{\circ} / 83 \mathrm{~km}$ \\
\hline Caladan Planitia 2 & 2/2011 (T74) & 12/2009 (T64) & $22.8^{\circ} \mathrm{N}, 219.5^{\circ} \mathrm{W}$ & $26^{\circ} / 26^{\circ} / 33^{\circ} / 83 \mathrm{~km}$ \\
\hline \multicolumn{5}{|l|}{ Variable Plains ( $p f v$ ) } \\
\hline N-S Dilmun & 5/2007 (T31) & 10/2005-02/2008 (T8/T41) & $12.3^{\circ} \mathrm{N}, 193.2^{\circ} \mathrm{W}$ & $12^{\circ} / 31^{\circ} / 25^{\circ} / 58 \mathrm{~km}$ \\
\hline Adiri & $12 / 2009$ (T64) & $2 / 2008(\mathrm{~T} 41)$ & $19.75^{\circ} \mathrm{S}, 183.4^{\circ} \mathrm{W}$ & $58^{\circ} / 29^{\circ} / 43^{\circ} / 43 \mathrm{~km}$ \\
\hline \multicolumn{5}{|l|}{ Streak-like plains (psh) } \\
\hline Winia Fluctus & 8/2005 (T6) & 12/2004-06/2010 (T0/T69) & $47.8^{\circ} \mathrm{N}, 45.5^{\circ} \mathrm{W}$ & $60^{\circ} / 42^{\circ} / 52^{\circ} / 42 \mathrm{~km}$ \\
\hline Tishtrya Virgae & 12/2011 (T79) & $12 / 2009(\mathrm{~T} 64)$ & $22.5^{\circ} \mathrm{N}, 179^{\circ} \mathrm{W}$ & $41^{\circ} / 38^{\circ} / 16^{\circ} / 65 \mathrm{~km}$ \\
\hline \multicolumn{5}{|l|}{ Scalloped plains (psv) } \\
\hline N Afekan & 9/2013 (T94) & 10/2006 (T19) & $59^{\circ} \mathrm{N}, 148.7^{\circ} \mathrm{W}$ & $45^{\circ} / 54^{\circ} / 84^{\circ} / 54 \mathrm{~km}$ \\
\hline NE Soi & $2 / 2007$ (T25) & 7/2006-10/2006 (T16/T19) & $54.3^{\circ} \mathrm{N}, 144.5^{\circ} \mathrm{W}$ & $58^{\circ} / 21^{\circ} / 69^{\circ} / 70 \mathrm{~km}$ \\
\hline \multicolumn{5}{|l|}{ Huygens landing site (HLS) } \\
\hline HLS & 12/2004 (Tb) & 10/2005 (T8) & $10^{\circ} \mathrm{S}, 192^{\circ} \mathrm{W}$ & $36^{\circ} / 34^{\circ} / 18^{\circ} / 15 \mathrm{~km}$ \\
\hline \multicolumn{5}{|c|}{ Hummocky/mountainous terrain (hh) } \\
\hline Gandalf Colles & 6/2010 (T70) & 6/2012 (T84) & $14.6^{\circ} \mathrm{N}, 209.8^{\circ} \mathrm{W}$ & $29^{\circ} / 19^{\circ} / 31^{\circ} / 15 \mathrm{~km}$ \\
\hline Unnamed Feature Near Belet & 9/2010 (T72) & 7/2013 (T92) & $0.7^{\circ} \mathrm{N}, 245.7^{\circ} \mathrm{W}$ & $11^{\circ} / 30^{\circ} / 23^{\circ} / 15 \mathrm{~km}$ \\
\hline Angmar Montes & 4/2007 (T29) & 10/2005 (T8) & $10.1^{\circ} \mathrm{S}, 221^{\circ} \mathrm{W}$ & $26^{\circ} / 13^{\circ} / 37^{\circ} / 74 \mathrm{~km}$ \\
\hline Echoriath Montes & 4/2007 (T29) & 10/2005 (T8) & $7.6^{\circ} \mathrm{S}, 215^{\circ} \mathrm{W}$ & $20^{\circ} / 17^{\circ} / 37^{\circ} / 74 \mathrm{~km}$ \\
\hline Mindolluin Montes & 3/2007 (T26) & 8/2009 (T61) & $2.5^{\circ} \mathrm{S}, 210^{\circ} \mathrm{W}$ & $09^{\circ} / 51^{\circ} / 60^{\circ} / 63 \mathrm{~km}$ \\
\hline \multicolumn{5}{|l|}{ Labyrinth Terrain (lb) } \\
\hline Junction & 9/2010 (T71) & 12/2007 (T39) & $47^{\circ} \mathrm{S}, 213.9^{\circ} \mathrm{W}$ & $58^{\circ} / 45^{\circ} / 34^{\circ} / 65 \mathrm{~km}$ \\
\hline Tleilax & $4 / 2005$ (T5) & $9 / 2005$ (T7) & $48.1^{\circ} \mathrm{S}, 15.9^{\circ} \mathrm{W}$ & $53^{\circ} / 56^{\circ} / 56^{\circ} / 28 \mathrm{~km}$ \\
\hline Richese & $6 / 2010(T 70)$ & 5/2012 (T83) & $41.7^{\circ} \mathrm{N}, 199.7^{\circ} \mathrm{W}$ & $50^{\circ} / 50^{\circ} / 31^{\circ} / 17 \mathrm{~km}$ \\
\hline \multicolumn{5}{|l|}{ Dune field (dl) } \\
\hline W Shangri-la & 10/2005 (T8) & 4/2006 (T13) & $5^{\circ} \mathrm{S}, 145^{\circ} \mathrm{W}$ & $45^{\circ} / 40^{\circ} / 20^{\circ} / 86 \mathrm{~km}$ \\
\hline NE Shangri-la & 2/2005 (Т3) & $7 / 2009$ (T58) & $7.5^{\circ} \mathrm{S}, 172^{\circ} \mathrm{W}$ & $22^{\circ} / 13^{\circ} / 19^{\circ} / 96 \mathrm{~km}$ \\
\hline Belet & $1 / 2010$ (T65) & $7 / 2013$ (T92) & $5^{\circ} \mathrm{N}, 237^{\circ} \mathrm{W}$ & $43^{\circ} / 23^{\circ} / 43^{\circ} / 91 \mathrm{~km}$ \\
\hline \multicolumn{5}{|l|}{ Crater Ejecta (ceh) } \\
\hline Selk & $1 / 2008(T 40)$ & 2/2014 (T98) & $7^{\circ} \mathrm{N}, 199^{\circ} \mathrm{W}$ & $34^{\circ} / 14^{\circ} / 34^{\circ} / 3 \mathrm{~km}$ \\
\hline Sinlap & 12/2005 (T9) & $2 / 2005(\mathrm{~T} 3)$ & $11.6^{\circ} \mathrm{N}, 15.4^{\circ} \mathrm{W}$ & $43^{\circ} / 13^{\circ} / 40^{\circ} / 13.5 \mathrm{~km}$ \\
\hline Soi & $12 / 2004(\mathrm{~Tb})$ & 7/2006-05/2009 (T16/T55) & $24.3^{\circ} \mathrm{N}, 141^{\circ} \mathrm{W}$ & $48^{\circ} / 38^{\circ} / 14^{\circ} / 40 \mathrm{~km}$ \\
\hline Afekan & $3 / 2007$ (T26) & $5 / 2008(\mathrm{~T} 43)$ & $25.8^{\circ} \mathrm{N}, 200.3^{\circ} \mathrm{W}$ & $40^{\circ} / 34^{\circ} / 60^{\circ} / 63 \mathrm{~km}$ \\
\hline Forseti & $4 / 2006(\mathrm{~T} 13)$ & $1 / 2007$ (T23) & $25.5^{\circ} \mathrm{N}, 10.4^{\circ} \mathrm{W}$ & $50^{\circ} / 19^{\circ} / 37^{\circ} / 11 \mathrm{~km}$ \\
\hline Menrva & $12 / 2008(T 48)$ & 2/2005 (T3) & $20.1^{\circ} \mathrm{N}, 87.2^{\circ} \mathrm{W}$ & $59^{\circ} / 59^{\circ} / 71^{\circ} / 11 \mathrm{~km}$ \\
\hline \multicolumn{5}{|l|}{ Alluvial Fans (af) } \\
\hline Out Xanadu & $12 / 2008$ (T48) & 6/2011 (T77) & $20^{\circ} \mathrm{S}, 118^{\circ} \mathrm{W}$ & $33^{\circ} / 38^{\circ} / 71^{\circ} / 62 \mathrm{~km}$ \\
\hline Xanadu \#1 & $12 / 2008$ (T49) & $6 / 2011$ (T77) & $17^{\circ} \mathrm{S}, 124^{\circ} \mathrm{W}$ & $25^{\circ} / 46^{\circ} / 71 \% / 62 \mathrm{~km}$ \\
\hline Xanadu \#2 & $5 / 2008$ (T44) & $2 / 2008(T 41)$ & $32.8^{\circ} \mathrm{S}, 93.5^{\circ} \mathrm{W}$ & $56^{\circ} / 27^{\circ} / 93^{\circ} / 15 \mathrm{~km}$ \\
\hline Xanadu \#3 & $11 / 2008(T 47)$ & 5/2008 (T43) & $25^{\circ} \mathrm{S}, 90.1^{\circ} \mathrm{W}$ & $60^{\circ} / 20^{\circ} / 81^{\circ} / 45 \mathrm{~km}$ \\
\hline Elivagar Flumina & 12/2008 (T49) & 10/2006 (T19) & $21^{\circ} \mathrm{N}, 77^{\circ} \mathrm{W}$ & $60^{\circ} / 20^{\circ} / 20^{\circ} / 68 \mathrm{~km}$ \\
\hline
\end{tabular}

Note. We use the terrain unit code as defined in Malaska et al. (2016) for the geomorphologic units. We added a codename (af) for the alluvial fans.

temporal variations of the undifferentiated plains and the dunes were studied in Solomonidou et al. (2016), who found that the dunes (from 2005 to 2012) and the undifferentiated plains (from 2010 to 2012) did not present any change in albedo with time.

In this study, we extend our investigation of the spectral nature of the major geomorphological units of Titan's low-latitude and midlatitude regions by characterizing the units based on the shape and value of their surface albedos. We then test the surface albedos against a database of Titan candidate ice and organic constituents and provide some constraints on the possible major material present in every geomorphological unit. We use a new updated material library based on Bernard et al. (2006), Brassé et al. (2015), and the 


\section{AGU Journal of Geophysical Research: Planets}

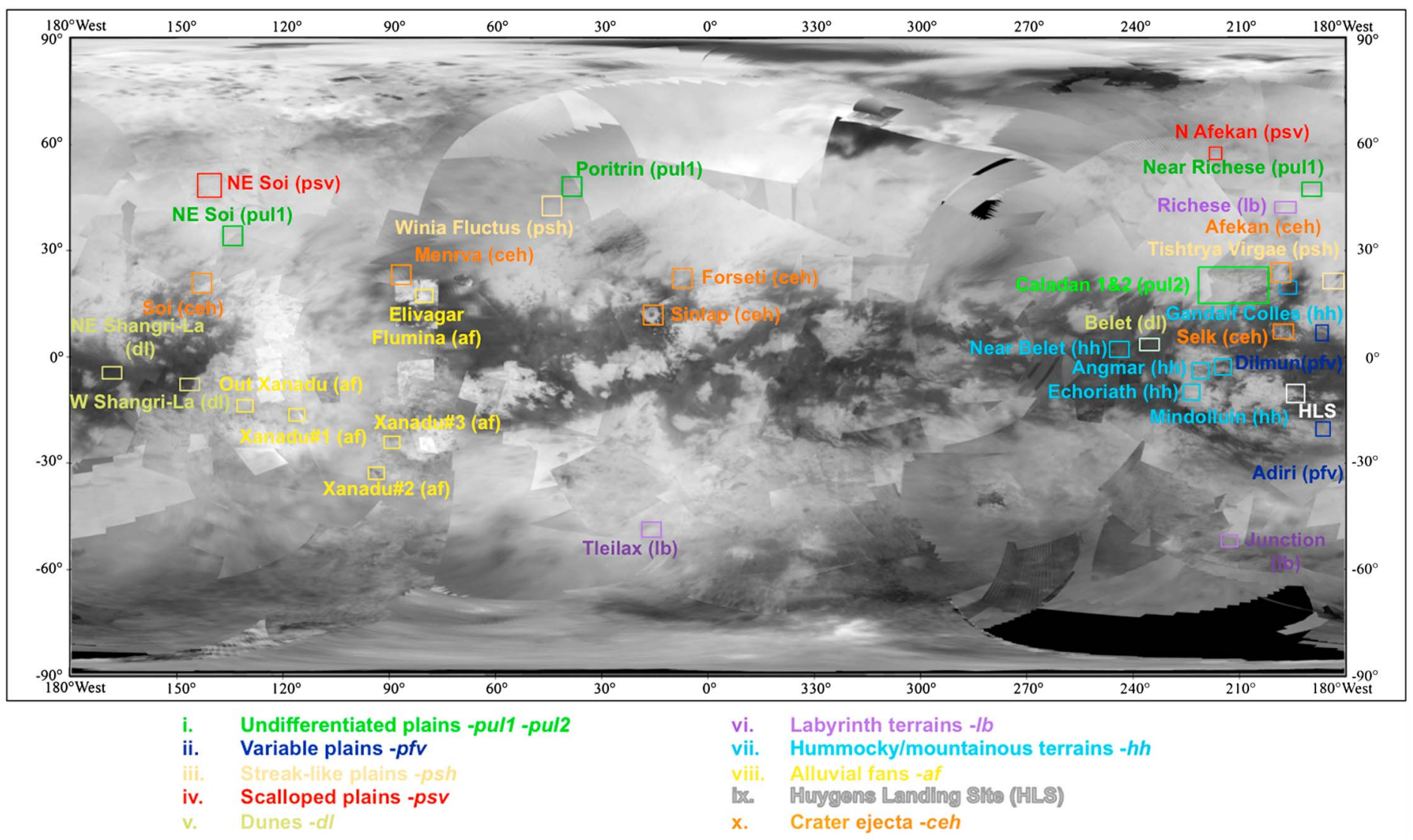

Figure 1. Selected regions of interest extracted from the major geomorphological units on Titan shown on a Cassini Visual and Infrared Mapping Spectrometer mosaic map at $2.03 \mu \mathrm{m}$. The characterization of the regions is based on morphological characteristics from studies by Lopes et al. (2010, 2016), Malaska et al. (2011, 2016), Neish et al. (2015), and Radebaugh et al. (2016). The basemap corresponds to a $2.03 \mu \mathrm{m}$ global map of Ta to T114 flybys (Le Mouélic et al., 2012, 2016).

GhoSST database (http://ghosst.osug.fr). Due to the complexity of the presence of the thick atmosphere that does not allow us to retrieve full surface spectra and of the difficulty of inferring material characteristics on a surface as complex as that of Titan's, we cannot provide actual compositions but rather insights on the possible major constituents for each geomorphological unit.

Below we analyze at least two representative examples of each of the above mentioned nine geomorphological units (Table 1), 34 different areas in total, to determine the characteristics of the units using VIMS and RADAR/SAR data, when available (Table 2 and Figure 1). We limit our VIMS datacube selection to the lowlatitude and midlatitude regions due to our RT code limitations at high latitudes and extreme geometries (Solomonidou et al., 2014, summarized below). We then test five individual undifferentiated plains (pul), five hummocky/mountainous terrains $(h h)$, three labyrinths $(I b)$, two variable plains $(p f v)$, three dune fields $(d l)$, two scalloped plains ( $p s v)$, two streak-like plains ( $p s h)$, six crater ejecta (ceh), and five alluvial fans (af) (see Table 1 and Lopes et al. (2016), Malaska et al. (2016), and Radebaugh et al. (2016) for the full descriptions). In Figure 1 we show Caladan Planitia 1 and 2 (two distinct regions of undifferentiated plains) in a single rectangular box called "Caladan Planitia" in addition to three more regions of undifferentiated plains. We also analyze the same HLS datacube selection from the Tb flyby as used for calibration and reference area in Solomonidou et al. $(2014,2016)$ and Lopes et al. (2016).

\section{Process and Method of Analysis}

\subsection{VIMS and SAR Overlapping}

The aforementioned geomorphological units are characterized based on their appearance on the SAR images (Lopes et al., 2010, 2016; Malaska et al., 2016). The scope of our study is to spectrally analyze 
these regions using VIMS data. However, because of the large differences in terms of spatial resolution that both types of data present (average spatial resolution for SAR: $\sim 175 \mathrm{~m}$, for VIMS: $\sim 50 \mathrm{~km}$, in the present analysis) and in order to ensure that we analyze the same region from VIMS and SAR data, we superimpose SAR on VIMS spectro-images. To do that, we employ a number of tools provided in the U.S. Geological Survey (USGS) Integrated Software for Imagers and Spectrometers 3 (ISIS3). In Figure 2, there are four columns that present our major Rols as examples for the undifferentiated, the variable, and the streak-like plains, the dunes, the hummocky, and labyrinth terrains, as shown in individual VIMS and SAR images and in overlaps between both data sets. Following this, we ensure that the VIMS pixel selection includes the geomorphological units of interest. The HLS Rol datacube and pixel selections are described in Solomonidou et al. (2014).

\subsection{VIMS Analysis}

Before the compositional properties of the surface can be extracted, we evaluate the atmospheric contribution included in the spectral (VIMS) data. As in our previous work, we apply to the data a plane-parallel RT code (RT, Hirtzig et al., 2013). Our code is based on the plane-parallel version of the Spherical Harmonic Discrete Ordinate Method solver (SHDOMPP; Evans, 2007). Titan's atmosphere is divided into 70 layers, and the calculations for each layer are based on the vertical profiles of pressure and temperature measured by the Huygens probe's Atmospheric Structure Instrument (Fulchignoni et al., 2005), the methane vertical mixing ratio from the Huygens Gas Chromatograph Mass Spectrometer (Niemann et al., 2010), and on a uniform CO mole fraction equal to $4.5 \times 10^{-5}$ based on Cassini Composite Infrared Spectrometer measurements (de Kok et al., 2007). Updates of the code and improvements on our method for albedo retrievals in the Rols were implemented and described in detail in Solomonidou et al. $(2014,2016)$, Bonnefoy et al. (2016), and Lopes et al. (2016).

The updates include improvement on the inference of the opacity from methane and its isotopologues using theoretical calculations, laboratory measurements, and empirical models from recent molecular line database upgrades such as included in HITRAN (Rothman et al., 2013) and in GEISA (Jacquinet-Husson et al., 2011) as described in Boudon et al. (2006), also from Campargue et al. (2012, 2013, and private communication), Nikitin et al. (2013), and Rey et al. (2018), and references therein. These recent methane line lists were installed in our RT model as a set of correlated-k absorption coefficients, applied here to the pressure and temperature conditions of Titan in the VIMS range $(0.89-5.2 \mu \mathrm{m})$. In order to be completely operational up to $5 \mu \mathrm{m}$, and to include the Huygens in situ aerosol data, our code slightly adjusts and extrapolates beyond $1.6 \mu \mathrm{m}$ the single scattering albedo given by Tomasko et al. (2008), based on the work of de Bergh et al. (2012) and Campargue et al. (2012, 2013), and references therein. It then interpolates in wavelengths and altitudes the opacities with the formula given in Tomasko et al. (2008), and the tabulated phase functions therein. The single scattering albedo is thus adjusted as shown in Figure 3b of Hirtzig et al. (2013). The total opacity is the multiplicative factor applied to the DISR vertical extinction profile. Finally, in our code, the surface is considered as Lambertian, which is compatible at first order with previous estimations of the general photometric behavior of Titan's surface (Le Mouélic et al., 2012; Schröder \& Keller, 2008). A recent addition to the code that helps with our compositional analysis is an extensive library of possible Titan materials for the surface provided mainly in the GhoSST database (http://ghosst.osug.fr). A more detailed description of the library can be found in section 3.3.

Uncertainties at the $3 \sigma$ level are also estimated by the code for the haze opacity and the surface albedo (Hirtzig et al., 2013; Solomonidou et al., 2014, 2016), taking into account on the one hand the aerosol forced single scattering albedo, the aerosol phase function, the aerosol vertical distribution, and the inverted aerosol total opacity. On the other hand, we also include the error bars due to the $\mathrm{CH}_{4}$ linelist, the $\mathrm{CH}_{4}$ far wing profile, and the $\mathrm{CH}_{4}$ vertical concentration profile. The signal-to-noise ratio is enhanced by averaging multiple spectra, which leads to an increase in the pixel-to-pixel $I / F$ variability, but not so much as to affect the average gain in signal.

Our whole data set of Rols (34 in total; see Table 2) represents nine different geomorphological units (Table 1). All VIMS datacubes we analyze here have geometry conditions compatible with our plane-parallel code, and this leads to adequate resolution for the appropriate region selection. The pixel selection was made very carefully and included only the Rols as described in section 2.1. 


\section{AGU Journal of Geophysical Research: Planets}

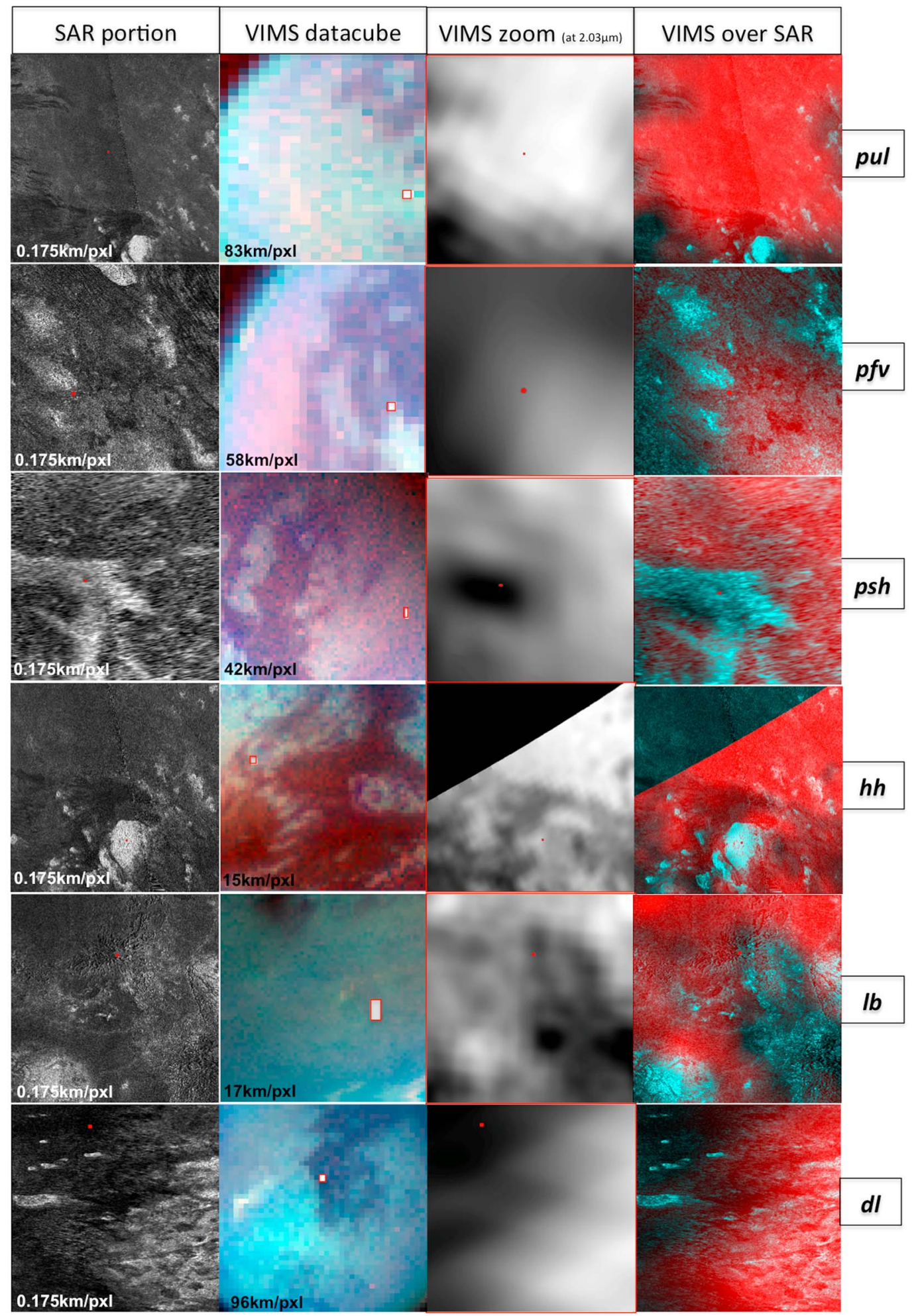

Figure 2. Regions of interest and pixel selection from top to bottom: undifferentiated plain (pul2—Caladan Planitia 1), variable plain (pfv-N-S Dilmun), streak-like plain ( $p h$-Winia Fluctus), hummocky terrain ( $h h$-Gandalf Colles), labyrinth terrain (lb-Richese), and dunes ( $d$ - NE Shangri-La). The first column shows the SAR image that includes the region of interest. The second column shows the full Visual and Infrared Mapping Spectrometer (VIMS) datacube (R: $5.00 \mu \mathrm{m}, \mathrm{G}: 2.03 \mu \mathrm{m}$, and B: $1.28 \mu \mathrm{m}$ ) with observation geometries adequate for a plane-parallel approximation and good enough resolution (the red box surrounds the image shown in the third column). The third column shows a zoom-in of the region of interest with VIMS at $2.03 \mu \mathrm{m}$ based on the equivalent SAR resolution that is showed in the first column using U.S. Geological Survey (USGS) Intergrated Software for Imagers and Spectrometers 3 (ISIS3) VIMS2ISIS method; the red dot represents the center of the area of interest. The fourth column is a combination of the figures showed in the first and third columns (R: $2.03 \mu \mathrm{m} / 1.28 \mu \mathrm{m}, \mathrm{G}: \mathrm{SAR}$, and B: SAR). 


\section{Results: Characteristics of the Various Surface Units}

After setting all the variables and inputs mentioned above, our code solves the RT equation to infer the characteristics of Titan's atmosphere and surface from the best possible fit to the VIMS spectrum (Figure 3) for each geomorphological unit.

\subsection{Haze Contribution and Surface Albedos Retrieved From the VIMS Data Analysis}

As a first step, we run RT code simulations with various haze opacities and after the best fit is obtained between the data and the simulations we derive the haze opacity for each data set with an uncertainty of about 15\%. The method and code are described in detail in Hirtzig et al. (2013) and in Solomonidou et al. (2014, 2016).

For an easier reading of the findings, we compare these haze values after calibrating them with the DISR value inferred at the HLS (the HLS haze is then set to $100 \%$ ).

The nominal haze contributions to the VIMS spectra we study here vary roughly from $-30 \%$ to $+20 \%$ of the "ground truth" DISR haze value at the HLS (Figure 4). Within error bars, Tiellax, Sotra Patera, Sangri-La, and Near Richese are compatible with the HLS measurements. On the other hand, the values differ from the HLS measurements with lower haze inferred in regions such as the Caladan Planitia undifferentiated plains, the Gandalf Colles hummocky terrain, the alluvial fans of Elivagar Flumina, the Adiri variable plain, and the Winia Fluctus while slightly higher haze content is found for the scalloped pains NE of the Soi crater and the Sinlap crater. This is indicative of variations in the atmospheric haze above these regions, which can be due to different atmospheric and meteorological causes, although we do not observe an obvious latitudinal pattern.

Following the estimation of the haze contribution to the VIMS data, the code infers full surface albedos for each wavelength (Figure 5, black curves) and then calculates weighted averages (Figure 5, blue points). By looking at the haze distribution, we find that for regions around low-latitude and midlatitude that we investigate here, there do not appear to be very large differences in haze contributions. In any event, any such differences are taken into account by the RT code in estimating the atmospheric contribution, which is then subtracted to infer the dynamical range of the albedos without atmospheric effects.

Figure 5 shows an example of full resolution surface albedo retrieval from which, for clarity purposes, we calculate single points of weighted averages of the surface albedo within the windows (Figure 5, blue points), with larger weights for channels with higher transmittance around the center. The spectral resolution (Full Width at Half Maximum, FWHM) is about $13 \mathrm{~nm}$ below $2.0 \mu \mathrm{m}$, increases up to $22 \mathrm{~nm}$ at $4.2 \mu \mathrm{m}$, and decreases to $18 \mathrm{~nm}$ at $4.8 \mu \mathrm{m}$ (Brown et al., 2004). In this paper, we essentially use the albedo averages as shown in the example of Figure 5 (blue points) but calculated for all units to compare with potential surface material candidates and infer composition that reproduces the spectral shape and values.

\subsection{Surface Albedo Classification}

After applying our method to all VIMS datacubes from the selected Rols, we confirm that the low-latitude and midlatitude areas precategorized as a single unit (e.g., hummocky/mountainous and variable plains) based on their morphological characteristics (Lopes et al., 2016; Malaska et al., 2016) have similar spectral responses as well. They have indeed the same or very similar (within error bars) surface albedos, as shown in Figure 6 , where the surface albedos of all labyrinth and dune examples are presented. This means that the RADAR and the VIMS spectro-imaging interpretations coincide. The only exceptions are the very extensive undifferentiated plains, as discussed in Lopes et al. (2016) and hereafter, that show latitudinal variations.

In Figure 7 we show the weighted averages of the surface albedo, using one example of Rol from each unit even though in our analysis we use two to six different datacubes from each one of them.

The albedo also generally shows a more or less steep decrease from 2.03 to $5 \mu \mathrm{m}$. In terms of brightness, we distinguish three main types of surface albedo responses, which are high, medium, and low, and correspond to Categories 1, 2, and 3, respectively (Figure 8). In decreasing order, the brightest regions (Category 1) are the scalloped plains, the undifferentiated plains 1, the labyrinths, and the streak-like plains; the intermediate in brightness (Category 2) are the alluvial fans, the crater ejecta, and the undifferentiated plains 2; the ones with lowest albedos (Category 3) are the HLS, the variable plains, the hummocky terrains, and the dunes (Figure 8). 

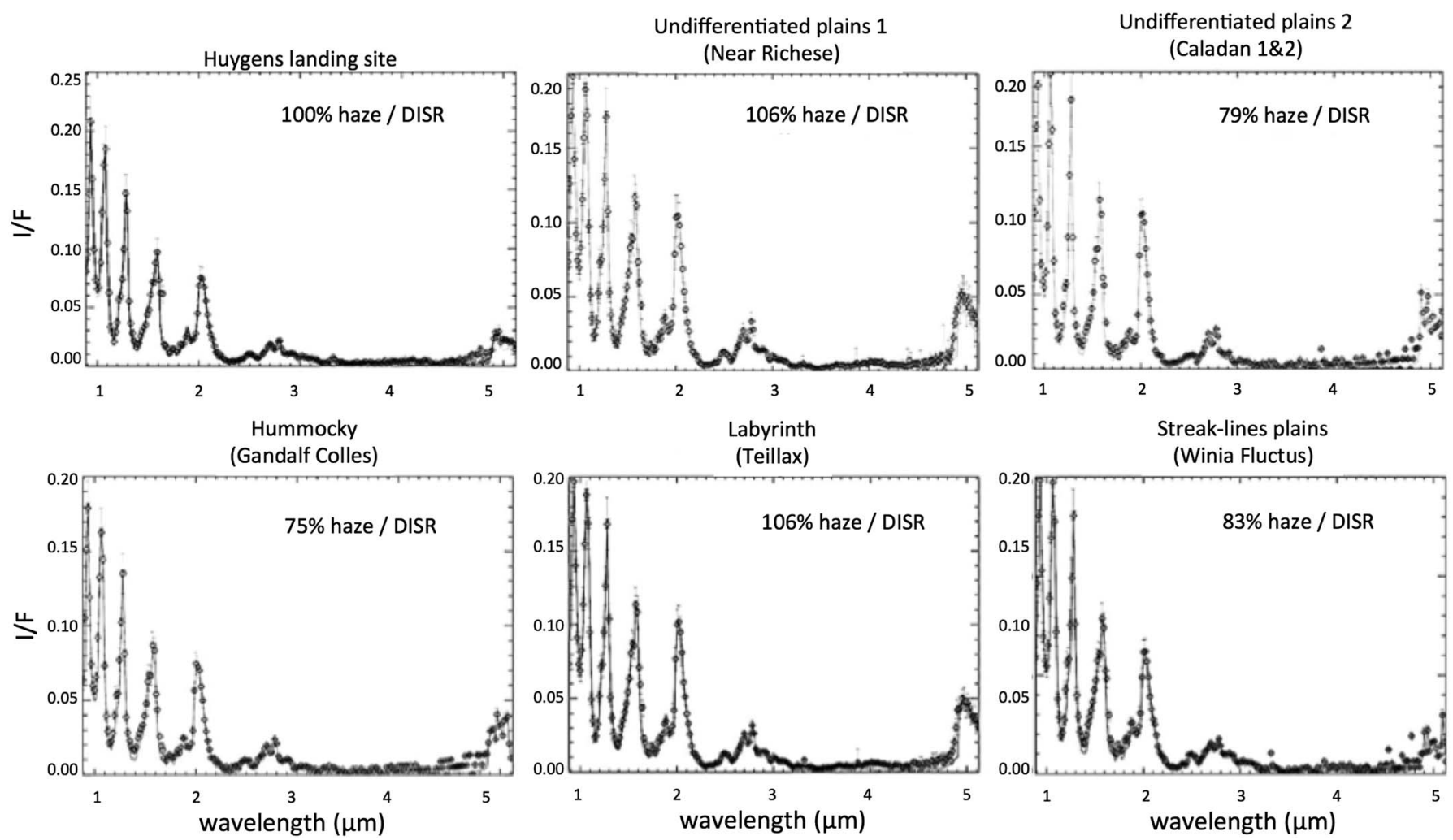

Figure 3. Best radiative transfer fits of the spectra for some of the geomorphological units such as the Huygens landing site (HLS), the two groups of undifferentiated plains, hummocky terrain (Belet), labyrinth terrain (Richese), and streak-like plain (Winia Fluctus). The haze contribution with respect to Descent Imager/Spectral Radiometer (DISR) that our radiative transfer code yields is given on each panel.

From Figure 8 (bottom), we find an important albedo similarity within the lowest albedo category between the HLS and the variable plains, with almost the same albedo values and shape. Indeed, the albedo values of the variable plain in Adiri (Table 2) are compatible within error bars with the albedo values at the HLS. This would be consistent with the variable plains and the HLS having similar chemical composition.

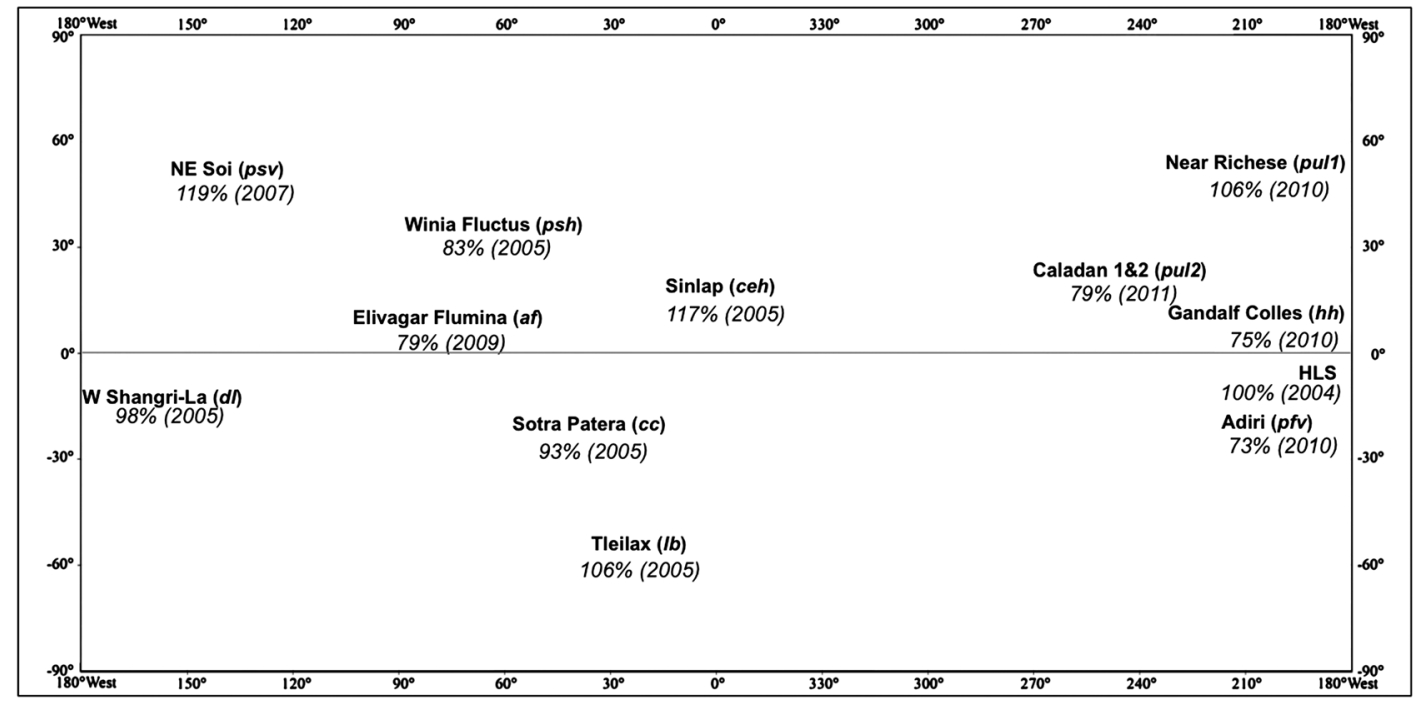

Figure 4. Estimated haze contributions in the Visual and Infrared Mapping Spectrometer data obtained from our radiative transfer simulations with respect to the Huygens/Descent Imager/Spectral Radiometer measurement using one example from each geomorphological unit and indicating locations and year of observation. 


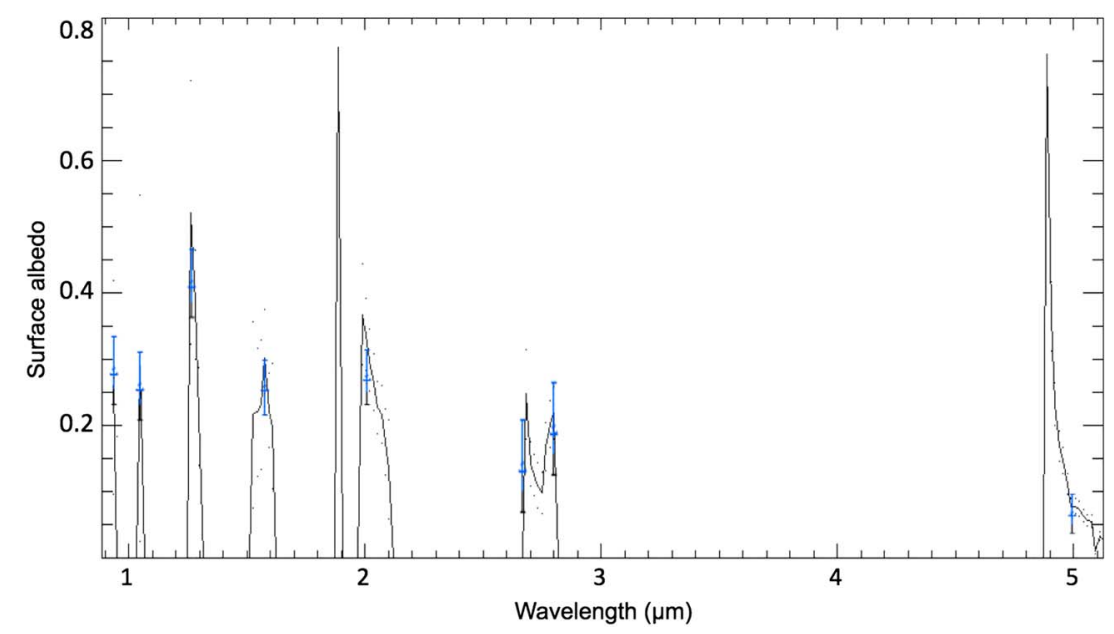

Figure 5. Full resolution surface albedo spectrum in the 0.89-5.2 $\mu \mathrm{m}$ Visual and Infrared Mapping Spectrometer range of the streak-like plain (Tishtrya Virgae) (black curves) that is used as an example here. The black dots correspond to the error bars envelopes. Weighted averages of the surface albedos in the methane windows (blue points).

We also find that we can confirm the results presented in Lopes et al. (2016) concerning examples of labyrinth terrains and dunes and also showing that the northern undifferentiated plains (Category 1 ) are significantly brighter than the undifferentiated plains that are close to the equator (Category 2).

The categorization of the results in Figure 8 reflects not only albedo values ranges but also several important common aspects in the spectral response behavior of each category that we highlight hereafter.

For Category 1, the 0.94 and $1.08 \mu \mathrm{m}$ albedo $(0.1-0.4)$ is about 2 times lower than the albedo from 1.28 to 2.69-2.79 $\mu \mathrm{m}$ (in the $0.2-0.65$ range), which is rather flat at high

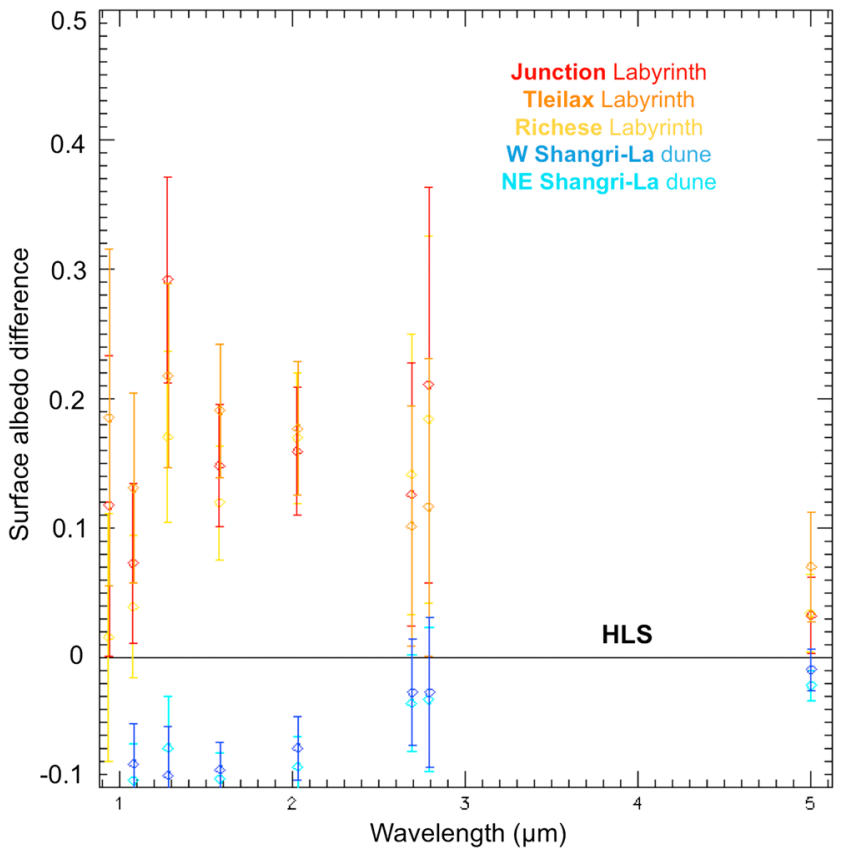

Figure 6. Weighted averages of the surface albedo (i.e., averages of the Visual and Infrared Mapping Spectrometer channels within the methane window, as for the example shown in Figure 5) for units described in Table 2: the various labyrinth terrains (red, orange, and yellow) and the dune terrains (light-dark blue). These are calibrated with respect to the HLS surface albedo (given in Figure 7). Within error bars, all labyrinth and also all dune terrains examined share the same albedo values and shape. values. There is then an abrupt drop toward $5 \mu \mathrm{m}$ (at 0.05-0.2) by factors of up to 3 .

For Category 2, similar to Category 1, there is an increase from 0.94 to $1.08 \mu \mathrm{m}$ to the albedo at $1.28 \mu \mathrm{m}$ (up to $\sim 0.4$ ) being distinctly the highest, but followed by a sharp drop afterward and toward 2.69-2.79 $\mu \mathrm{m}$, and then showing a continuous decrease down to $5 \mu \mathrm{m}$ by factors of up to 4 .

For Category 3, the $0.94-1.28 \mu \mathrm{m}$ range exhibits the highest albedo response $(0.15-0.35)$, followed by a continuous slowly descending slope from 1.59 to $5 \mu \mathrm{m}$ (by factors of 2-3).

This indicates different regimes in the spectral response of the various regional categories, essentially identifying the presence of composition and/or physical processes variances. The general trends are for rather dark regions when looking at longer wavelengths beyond $2 \mu \mathrm{m}$ rather than at shorter ones except 0.94 and $1.08 \mu \mathrm{m}$. The $5 \mu \mathrm{m}$ albedo is always the darkest. We indicate here also with some specific characteristics rising mainly from differences in the components influencing the $1.59-2.69-2.79 \mu \mathrm{m}$ region.

\subsection{Compositional Tests With Some Potential Major Constituents}

In order to provide insights on the composition of the geomorphological units studied here, we test the extracted albedos of the various units against three major constituents that are expected to be present in some form or other on Titan's surface. We do this by introducing into our RT code laboratory spectra produced in Titan conditions in 


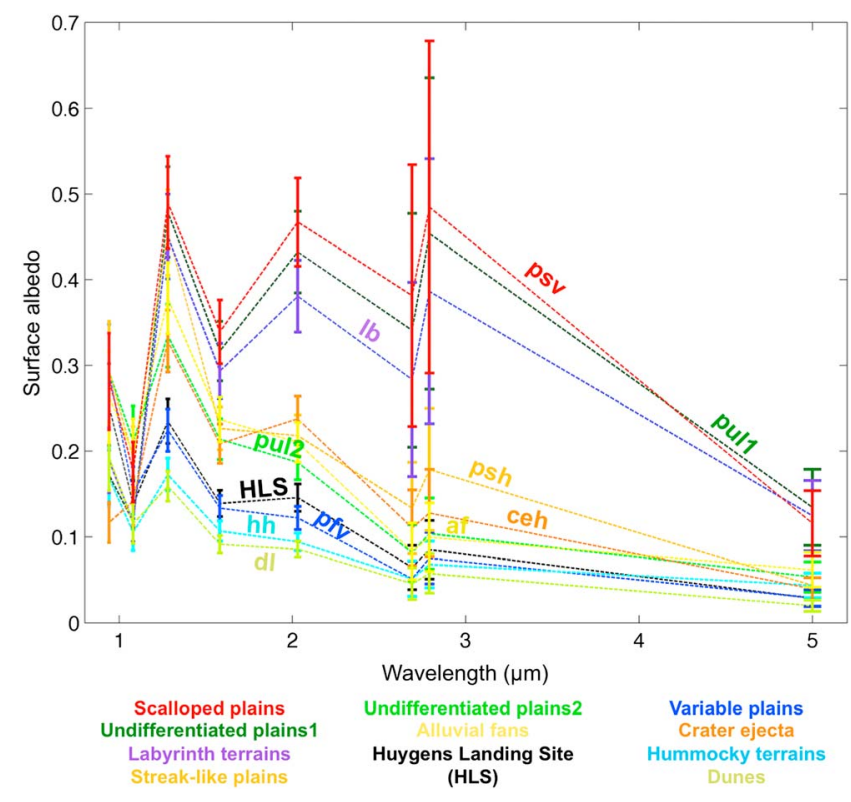

Figure 7. Weighted averages of the surface albedos in the methane windows of the various geomorphological units using one example from each unit. For clarity purposes, we have connected the points with dashed lines that do not represent a real physical spectral behavior but help to identify more easily the spectral shape for each unit over the whole wavelength range. the VIMS range $(0.89-5.2 \mu \mathrm{m})$. We thus have included (i) water ice, (ii) laboratory tholins, and (iii) bitumen and amorphous carbon (from the GhoSST database, http://ghosst.osug.fr, and from Bernard et al., 2006; Brassé et al., 2015; and Lellouch, 2006).

Our own database of reflectance spectra covering the VIMS spectral range at the VIMS resolution was thus calculated for each constituent. For $\mathrm{H}_{2} \mathrm{O}$ ice it was calculated for a series of 15 grain sizes from $10 \mu \mathrm{m}$ to $1 \mathrm{~mm}$ $(10,20,30,40,50,75,100,150,200,250,300,400,500,750$, and $1,000 \mu \mathrm{m}$ ). We used the SPECTRIMAG radiative transfer code (Douté \& Schmitt, 1998) that allows to calculate the bidirectional reflectance factor of a granular surface with a certain grain size and illuminated under an incidence angle $i$ and observed under an emergence angle $e$. We assumed an isotropic particle scattering function for all ices as we have no a priori knowledge of what this is on Titan. The optical constants of crystalline $\mathrm{H}_{2} \mathrm{O}$ ice were derived from several experiments performed at the Institut de Planétologie et d'Astrophysique de Grenoble (France) in the nearinfrared (IR) and mid-IR (Trotta \& Schmitt, 1996; Grundy \& Schmitt, 1998; Schmitt et al., 1998). The closest temperature to Titan's conditions of the data set available in both the near-IR and mid-IR is $145 \mathrm{~K}$, but we consider this to be adequate for our simulations in view of the relatively low spectral resolution of the VIMS data compared to the rate of temperature band shifts of the ice (Grundy \& Schmitt, 1998). The laboratory tholins are produced at six different grain sizes (1, 2, 5, 10, 30, and $100 \mu \mathrm{m})$ (Figure 9). The dark materials are asphalite, kerite, different types of anthraxolite, and amorphous carbon at three different grain sizes (10, 200, and $500 \mu \mathrm{m}$ ), which have been suggested as being similar to materials capable of lowering the total surface albedo in many Titan areas (Solomonidou et al., 2014, 2016) (Figure 9).

In this paper, we try to fit the Titan albedos using only these three constituents and linear mixtures thereof. We acknowledge that this is a simplistic assumption, as Titan's surface is likely to be far more complex than made solely of spatial distributions of the above types of compounds. We do not expect perfect fits to the data; we simply test to what extent we can match the available observations that we classified spectrally in Figure 8 in terms of absolute values and general spectral shape with these basic constituents. Figure 10 shows the extracted mixtures that best match the suite of surface albedo averaged points of the three different categories as defined in Figure 8.

Figure 10 shows the results of our calculations for inferring the major constituent in different geomorphological categories as described in Figure 8. Our simulations provide the best possible fit for all the windows simultaneously, minimizing the residuals. We could not obtain a perfect match to any of the surface albedo spectra, as is expected by the use of only three basic components in the mixtures (water ice, tholins, and dark constituents). We find it particularly difficult to reproduce the 0.94 and $1.08 \mu \mathrm{m}$ albedo, especially for the high albedo values. The absence of a fit at those two wavelengths for most if not all regions points to the lack of a component that is very dark at these smaller wavelengths, while bitumen-like and amorphous carbon spectra (Figure 9) alone do not work. Perhaps a constituent with a strong absorption at these wavelengths would be required. Furthermore, the $1.08 \mu \mathrm{m}$ strong absorption (in 10 out of 11 cases presented in Figure 10 the $0.94 \mu \mathrm{m}$ surface albedo is higher than at $1.08 \mu \mathrm{m}$ ) could be indicative of a nonmolecular in nature surface component. Hence, a material compatible to silicates, such as orthopyroxene, could be a good fit to those short wavelength strong absorptions. However, such constituents are not compatible with current models of Titan's internal structure and do not constitute good candidates for the surface. We also do not find solutions with this basic composition for the $2 \mu \mathrm{m}$ methane window albedo values, again probably identifying the need for an absorbent at these wavelengths. With these caveats in mind, we do obtain fits within error bars for the other five out of eight methane windows and we find that the regional categories distinguished in Figure 8 can be matched with the same major constituent on their surfaces for each one of them, except for the unit of undifferentiated plains that are close to the equator. Thus, the categories in Figure 8 enter the 

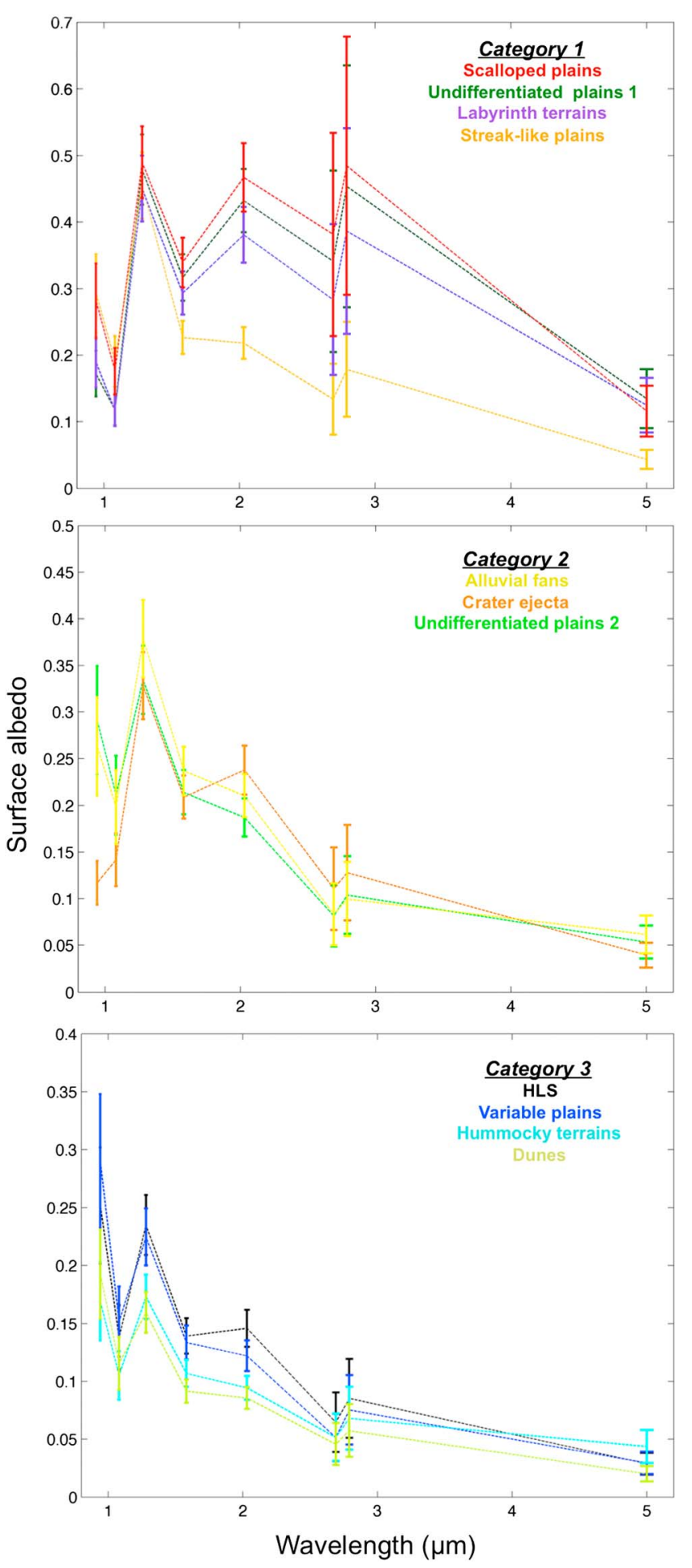

Figure 8. (top) This figure groups different geomorphological units as a function of surface albedo values and shapes. Surface albedo weighted averages are given for three different categories. Note the change in scale. See text for details. same compositional groups (CGs) in Figure 10, which is explained by their surface spectral characteristics corresponding to those of the spectroscopic parameters for one of the components used in our simulations.

Figure 10 (top) corresponds to compositional group 1 (CG 1) and shows the simulations that best match the VIMS data in units with the highest surface albedos in the methane windows between 1.28 and 2.69-2.79 $\mu \mathrm{m}$ and the spectral behavior of Category 1 (Figure 8). Our calculations show that these albedo spectra are best reproduced with water ice as the major constituent in any mixture of the three components we use here (at rates of $45-85 \%$ ). The simulated mixture for the scalloped plains is even more dominated by the water feature (Figure 9) and therefore has too high albedo at 0.94 and $1.08 \mu \mathrm{m}$ preventing us from matching the low albedo in these two methane windows, even with the addition of a dark component. The rest of the spectra in this CG 1 can be fit reasonably well except for 2.03 and $2.79 \mu \mathrm{m}$. The streak-like plains seem to have an intermediary behavior between the categories of surface albedos that are compatible with both $\mathrm{H}_{2} \mathrm{O}$ ice (CG 1) and tholin-like material (CG 2) as major constituents. Our findings here strongly indicate that water ice alone, even if dominant in a region cannot be pure and requires more than one additional component with dark features and/or a strong absorption at 0.94 and $1.08 \mu \mathrm{m}$ and a less absorbent component for 2.03 and $2.79 \mu \mathrm{m}$.

Figure 10 (middle) shows the alluvial fans and the crater ejecta to have materials with a spectral response similar to laboratory tholins dominating their mixtures (by 50-55\%). In this compositional group 2 (CG 2), the alluvial fans present a general good fit within error bars or close enough between the mixtures and the major constituent except at 1.28 and $2.03 \mu \mathrm{m}$, indicative that the tholin-like material is really dominating in these regions with need for a minor component to complete the composition. On the contrary, for the crater ejecta, the fit is very difficult everywhere and in particular at $0.94,1.08,2.03$, and $5 \mu \mathrm{m}$. We have placed the crater ejecta in this group because fits with other major constituents are even worse, but we recognize that in this case, several other components are required besides the three used here to match the observations. This could be due to the different epochs, impact objects, and processes related to their formation.

For compositional group 3 (CG 3; Figure 10, bottom), corresponding to units from Category 3 in Figure 10 (including pul2), a very dark material (that we attempt to simulate with bitumens and amorphous carbon from our database) appears to be the predominant constituent (by 50-80\%) of the variable plains, the HLS, the dunes, the hummocky terrains, and the undifferentiated plains that are close to the equator. There is a good fit between the mixtures and the surface albedos for all units except strikingly at 1.08 (except for pul2), 2.03, and $2.79 \mu \mathrm{m}$, as well as at $1.28 \mu \mathrm{m}$ for the undifferentiated plains.

Looking at the regional distribution of our results and at secondary components, the spectral response of the northern undifferentiated plains (such as Poritrin Planitia, the plains near Richese labyrinth, and the plains NE of Soi crater) appears to be compatible with a combination of a water ice-like component with materials similar to laboratory tholins. In contrast, the Caladan Planitia plains, which are closer to the equator and the Belet sand sea, appear to be compositionally dominated by a very dark material as a major constituent, possibly due to contamination by a dark albedo material from the 

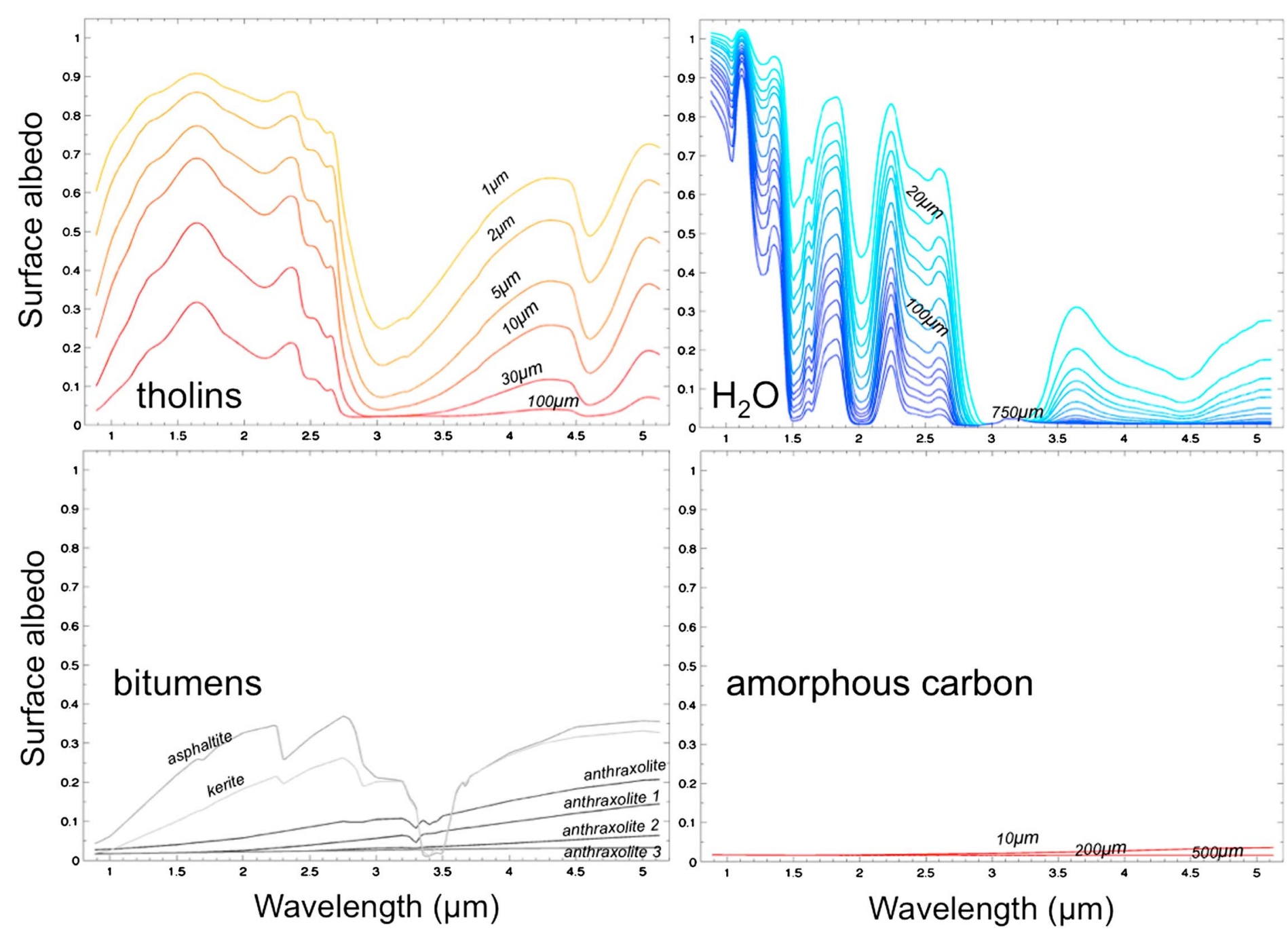

Figure 9. Spectra of Titan's surface and major candidate components in the Visual and Infrared Mapping Spectrometer range at different grain sizes (Bernard et al., 2006; Brassé et al., 2015; GhoSST database, http://ghosst.osug.fr).

equatorial dunes. In our previous study (Lopes et al., 2016), we used the Grundy and Schmitt (1998) $\mathrm{H}_{2} \mathrm{O}$ ice library to compare with the undifferentiated plains and labyrinth albedos and we argued that the northern undifferentiated plains and the labyrinths consist mainly of a material with a spectral response similar to that of laboratory tholins. In the current study, we used the same five different locations of undifferentiated plains as in Lopes et al. (2016), but applied the updated RT code as described in section 2.2 and the new $\mathrm{H}_{2} \mathrm{O}$ ice spectra from the GhoSST database (Figure 9). This update provided us with an improved fit between the albedos and the mixtures. Compared to that previous study, we find that both the northern undifferentiated plains and the labyrinth terrains are rich in a water ice-like material.

In this paper, we examined various geomorphologic units such as different types of plains (undifferentiated, variable, streak-like, and scalloped), crater ejecta, dunes, alluvial fans, hummocky, and labyrinth terrains. Our analysis begins by first evaluating the contribution of the atmosphere and then inferring the surface albedos by use of a RT code to extract the spectral behavior of the surface properties. We have categorized the different units according to their characteristics of their surface albedo spectra (Categories 1-3; Figure 8).

The albedo differences among the various surface units that we report here may correspond (at least partly) to compositional variations, as previously suggested by (among other) Soderblom, Kirk, et al. (2007), Solomonidou et al. (2014), and Lopes et al. (2016). In addition, different studies have suggested interpretations for the nature of the various units and their probable origin mainly either using RADAR data (e.g., 

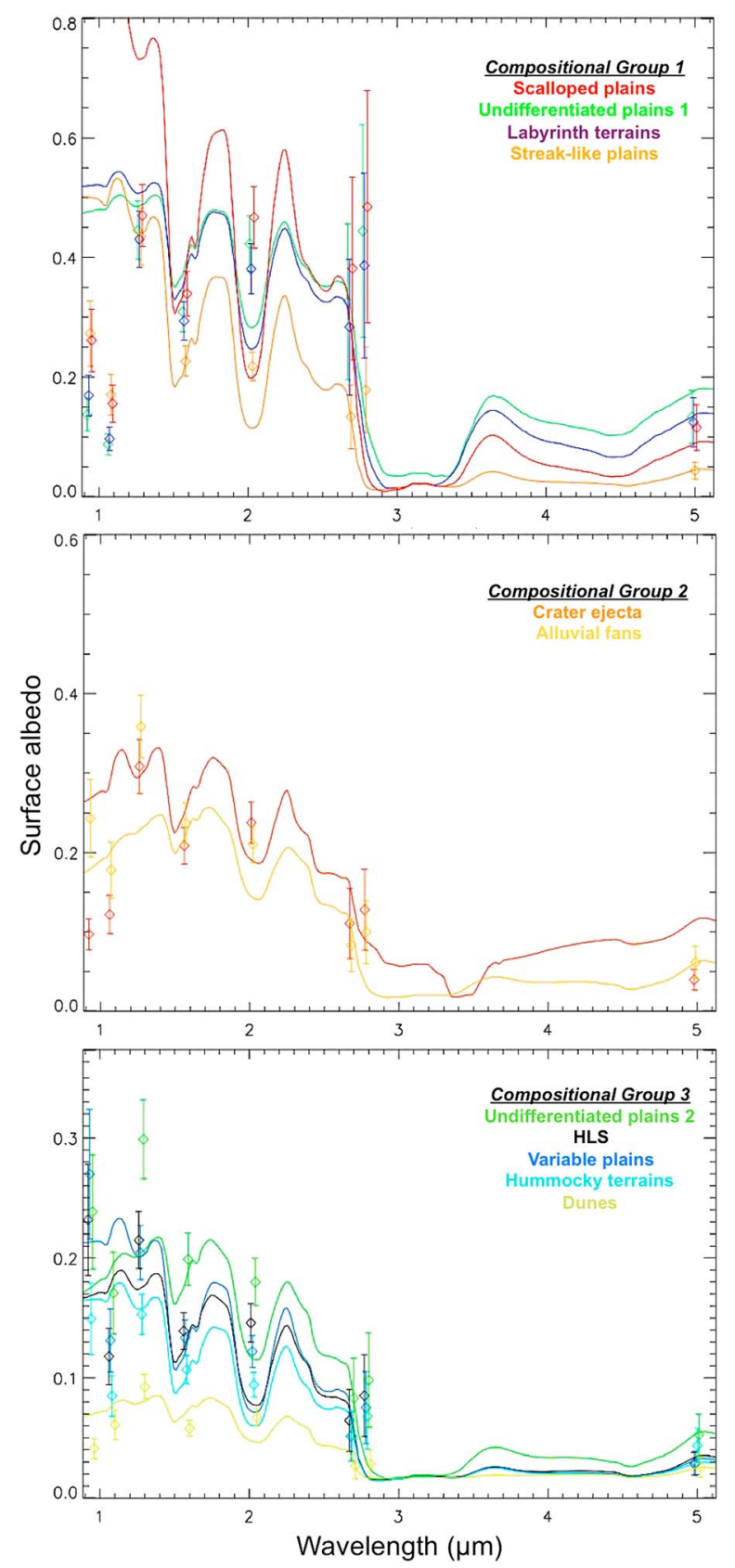

Figure 10. Inferred major constituents for all the geomorphological units categorized in Figure 8 using mixtures of water ice, tholins, and dark components. Note the change in scale. The point symbols correspond to the extracted surface albedos as shown in Figure 8, and the full lines to the compositional simulations, which are produced by the code using the best fit attained between the laboratory spectra and the albedos. The $3 \sigma$ error bars are shown on the simulations and are inferred by the code during the extraction of the surface albedos (detailed description of the $3 \sigma$ error bars can be found in section 2.2). For compositional group 1 with the highest surface albedo in the methane windows between 1.28 and $2.69-2.79 \mu \mathrm{m}$, we find the major constituent to be water ice (by percentages of about $45-85 \%$, with grain sizes mostly of 10 and $75 \mu \mathrm{m}$ ); for compositional group 2 we find tholin-like materials to be dominant (by $50-55 \%$, with grain sizes mostly of $100 \mu \mathrm{m}$ ); and dark constituents (with $50-80 \%$, mostly amorphous carbon of $200 \mu \mathrm{m}$ grain size) better satisfy the lower-albedo surface spectra of compositional group 3.
Janssen et al., 2016; Malaska et al., 2016) or using VIMS or a combination of both data sets (e.g., Barnes et al., 2005, 2007; Lopes et al., 2016; Malaska et al., 2016; Soderblom, Kirk, et al., 2007; Solomonidou et al., 2014).

In this study we compare our regional categories to linear mixtures of a few possible surface main candidates (water ice, tholin-like material, and dark components) from laboratory work and derive some insights on the major constituent(s) present at each unit's surface (Figure 10).

We have shown that the fit between the extracted surface albedo from the units and the possible mixtures is not optimal for all cases (there is, in particular, rarely a fit at very short wavelengths), which is indicative of a more complex surface than supposed in our simulations. Indeed, the code produces simulations with a number of different materials and grain size combinations from the three basic components $\left(\mathrm{H}_{2} \mathrm{O}\right.$ ice, tholins, and dark components) in order to obtain the best possible fit. The code generally finds a reasonable fit at 1.28, 1.59, 2.69, and $5 \mu \mathrm{m}$ for all the units. However, we can mostly not reproduce the lower surface albedos at 0.94 or $1.08 \mu \mathrm{m}$ in several cases, possibly due to lacking a component to compensate for the remaining absorption observed at these wavelengths. We also have a concern for 2.03 and $2.79 \mu \mathrm{m}$, where our mixtures produce too much absorption. Nevertheless, the code finds a match for at least one of the units in each group in all the methane windows in the VIMS range except systematically at 2.03 and $2.79 \mu \mathrm{m}$ and occasionally at $0.94 \mu \mathrm{m}$. The fact that we were able to fit some of the units in each group and not all the same way points at small but significant differences in the composition within each group, so we should not consider each category as having generally the same composition everywhere.

Even if we consider Rols in the undifferentiated plains (i.e., same geomorphological unit based on RADAR data), we would not have expected identical spectral behavior and, by extrapolation, chemical composition. Where composition is concerned, the differences can be due to the material (mixtures) and/or grain sizes. The problem is intricate and complex but, as a first step, we can focus on the spectral characteristics of the major constituent that we find to be dominating the surface albedo of regions that are of the same geomorphological unit (Figure 11).

Bearing in mind the limitations described above and by analyzing nine of the major geomorphological units from low-latitude up to midlatitude, we suggest that Titan's equator is dominated by a very dark unknown (most likely organic) component in a mixture with tholin-like materials, while extensive regions at midlatitudes seem to be rich in materials with a spectral response similar to water ice.

Our results indicate three groups of composition mixtures (CG) to be present on Titan's low-latitude and midlatitude surface region. In Figure 11 we plot the regions on an Imaging Science Subsystem global map, and hereafter we compare with previous work and additional insights from geological aspects.

Units with a spectral response similar to water ice: The presence of water ice on the surface of Titan has been a controversial issue. A study by Clark et al. (2010) refuted the presence of exposed water ice due to the high absorbance at $2.8 \mu \mathrm{m}$ compared to the $2.7 \mu \mathrm{m}$ one. Other studies report the presence of water ice on the surface of Titan by both telescopic (Griffith et al., 2003) and VIMS studies (McCord et al., 2006). The McCord et al. 


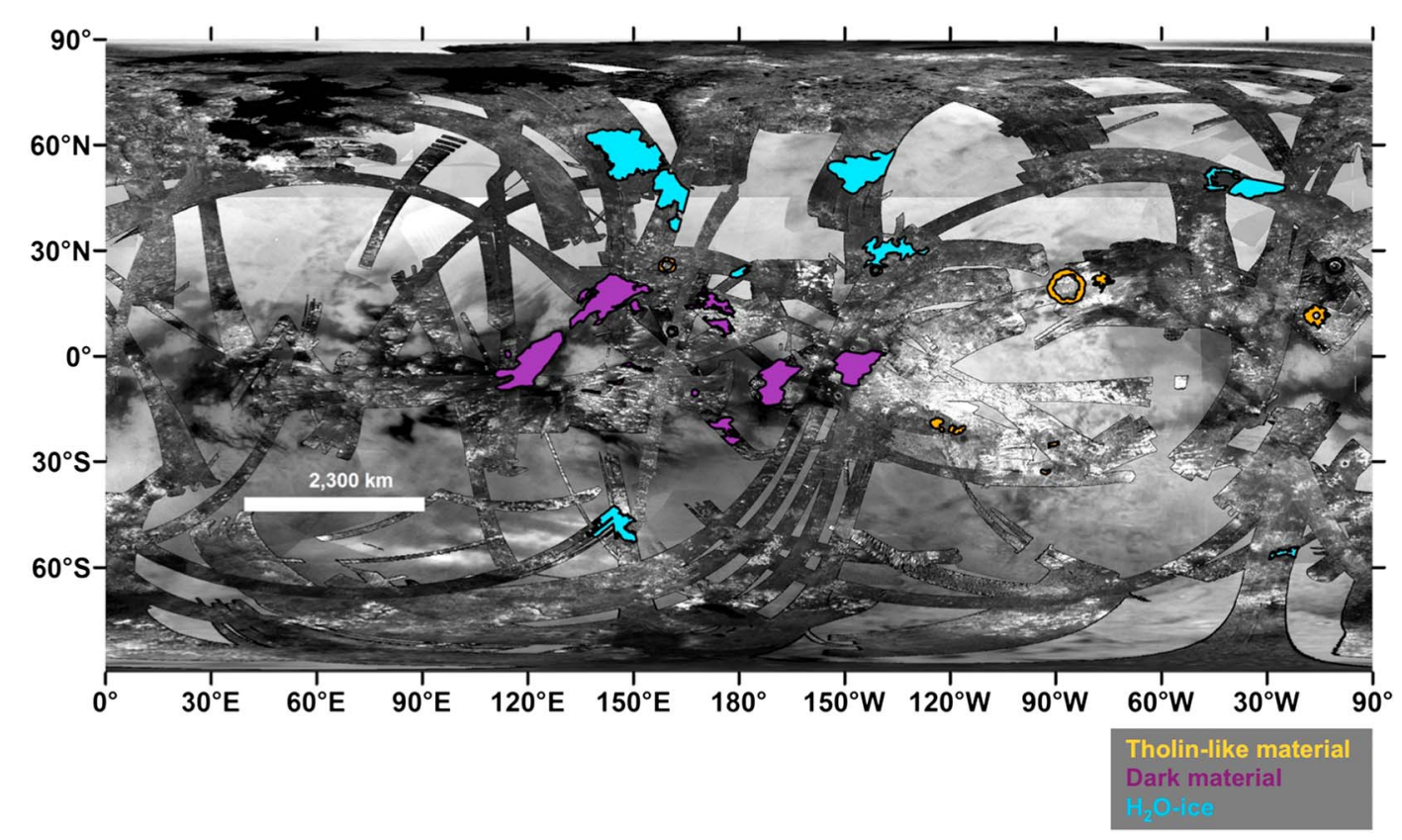

Figure 11. Implications on the major constituents of Titan regions of interest. The Imaging Science Subsystem global map (National Aeronautics and Space Administration/Jet Propulsion Laboratory-California Institute of Technology/Space Science Institute-PIA14908) is placed under the SAR swaths for context. The blue-colored regions correspond to regions where the major constituent in the mixture is an OH-bearing constituent, the magenta is an unknown dark material, and the orange is a tholin-like material.

(2006) study discussed the presence of two compositional classes associated with regions of low and high albedos. The areas low in surface albedo were suggested to be composed by water ice contaminated with dark material, while the high albedo areas seemed water ice-free. Hence, our study agrees with that of McCord et al. (2006) on the presence of water ice on the surface of Titan, which seems to be present and exposed on the surface, but not on where it is concentrated. According to Malaska et al. (2016), the streaklike plains are a combination of fluvial-aeolian processes in origin and consistent with the presence of water-icy material, while the scalloped plains are composed of either organic materials or extensively eroded hummocky materials. Furthermore, according to Malaska et al. (2016) and Lopes et al. (2016), the labyrinth terrains are interpreted to be dissected plateaux of organic materials based on SAR and radiometry data. Our results showed that these three units belong to the same compositional family, having a material compatible with water ice as the major constituent ( 45-85\%) on the surface. Moore et al. (2014) suggested sedimentation as the dominant geological process that forms the undifferentiated plains. Janssen et al. (2016), Lopes et al. (2016), and Malaska et al. (2016) agree on the nonwater ice nature of the undifferentiated plains and their probable aeolian-sedimentary origin. Here after testing a number of regions in the undifferentiated plains, we report two distinct spectral groups, confirming the results by Lopes et al. (2016), and suggesting the presence of mixtures containing tholin-like material and water ice-like material. The latter one is a new result coming from the present analysis. The undifferentiated plains with abundant water ice-like material in their mixtures are located in high (over $30^{\circ} \mathrm{N}$ and lower than $30^{\circ} \mathrm{S}$ ) latitudes.

Tholin-like rich units: The alluvial fans and the crater ejecta units are shown to contain mainly tholin-like materials (50-55\%). However, it is important to note that due to the limited spatial extension of these two units compared to the others, and the average low resolution of the VIMS data, their results could be subject to mixture with another unit within the same VIMS pixel, for instance, the inevitable mixing of the spectra of the rim and the interior of the crater. Nevertheless, we have tried to overcome that issue, as well as possible, by using the VIMS/SAR overlapping described in sections 2.1 .

Units covered with an unknown dark constituent: The hummocky/mountainous terrains, according to Lopes et al. (2016) and Malaska et al. (2016), are consistent with fractured water ice mixed with organic materials, based on microwave emissivity data (Janssen et al., 2009, 2016). The variable plains appear to have been 
produced from the erosional breakdown of the hummocky and mountainous units due to fluvial processes, and their primary surficial material, according to VIMS analysis, appears to be tholin-like rather than water ice-like (e.g., Moore et al., 2014). Furthermore, many studies have described the composition of the dune regions as organic material grains of aeolian origin (Barnes et al., 2008; Janssen et al., 2009, 2016; Le Gall et al., 2011; Lopes et al., 2016; Rodriguez et al., 2014; Soderblom, Kirk, et al., 2007; Solomonidou et al., 2016; Williams et al., 2011). Here for the two different examples of hummocky terrains that we tested, it seems that the major constituent is a very dark unknown material ( 70\%). Similarly, the variable plains, the dunes, and the HLS that also present very low albedo values are consistent with a dark material as major constituent (50-80\%) (Figure 11).

For the specific units that we tested, we showed that Rols with the same geomorphological unit classification also share the same or very similar spectral characteristics (examples shown in Figure 6). Exceptions are several regions of undifferentiated plains at different latitudes, which share the same morphological characteristics but differ in terms of the spectral values depending on latitude (but not in the overall spectral response). Hence, regardless of the location on Titan, the regions that are classified based on their morphological characteristics using SAR data by Lopes et al. (2016), Malaska et al. (2016), and Radebaugh et al. (2016) as members of the same geomorphological unit (e.g., variable plains, labyrinth terrains, and alluvial fans), have the same spectral characteristics in VIMS data and the RT analysis shows them to have at least the same major constituent. In conclusion, there is a profoundly good correlation in the classification between VIMS and SAR and the VIMS data validate the mapping of SAR.

In addition, the HLS and the variable plains share many albedo characteristics (Figure 8) suggesting that HLS is part of this unit and has an organic origin or is at least coated with organic materials. The same applies to the hummocky terrains and the dunes that are also compatible with an organic surficial composition (Figure 10). The alluvial fans and the crater ejecta units are covered by tholin-like material and seem to be dominated by atmospheric deposits that mask their underlying material. The areas with major constituents spectrally compatible with water ice seem to follow a geographical pattern as all four (northern undifferentiated plains, labyrinths, scalloped plains, and streak-like plains) are located at northern or southern midlatitudes, close to $30^{\circ}-60^{\circ} \mathrm{N}$ and $60^{\circ} \mathrm{S}$ (Figure 11). Hence, Titan's surface composition has a significant latitudinal dependence.

\section{Discussion: Implications and Interpretations}

Taking into consideration our results, we discuss hereafter some possible interpretations.

Our results suggest the presence of a material compatible with water ice in the areas around high latitudes. However, radiometry data have shown that water ice in large quantities is not expected in these regions given the absence of the detection of a high dielectric constant compatible with water ice 1 (Janssen et al., 2016). Based on that, we can provide a hypothesis for the presence of a low-dielectric (likely organic) material that has the same or similar infrared absorbance as water ice that can be deposited (or processed easily) from the atmosphere. However, VIMS probes only the thin top layer covering the surface and not the deeper parts that radiometry is measuring; hence, the presence of a thin coating of water ice or of a material with the spectral response similar to water ice covering a layer with organic material of low-dielectric constant is possible. If this hypothesis is true, it means that more dark material is being deposited from the atmosphere onto the equatorial regions compared to the higher and polar regions. In addition, the crater ejecta units (which we found consistent with $55 \%$ laboratory tholin, $25 \%$ water ice) that are concentrated between $30^{\circ} \mathrm{S}$ and $30^{\circ} \mathrm{N}$, may have penetrated the surficial organic layers after impact and reached into the water ice crust exposing it. Atmospheric material may have subsequently covered them again. This would provide a spectral coating consistent with a mixture of organic materials and water ice in impact craters, as suggested by Neish et al. (2015). Below this covering, the emissivity is consistent with water ice materials (Janssen et al., 2016; Malaska et al., 2016). Furthermore, the alluvial fans seem to be a mixture of materials that are carried by Titan's methane rivers (e.g., Lorenz et al., 2008). In the case of hummocky and mountainous materials, radiometry suggests a composition more compatible with water ice. The VIMS results presented here indicate a surficial composition compatible with organics. This difference in results could again be due to differences in depth sampled by the two instruments and be complementary instead of contradictory. This could also indicate the same latitudinal dependence described earlier for the case of impact craters. Finally, the 
results agree with the sedimentary nature of the undifferentiated plains, but at higher latitudes their coating seems to be thinner (less aeolian deposition), and therefore, our results could indicate a mixture of icy crust and aeolian materials.

In an alternative interpretation, we assume that atmospheric deposition is similar in the low-latitude and midlatitude on Titan, but with more rain falling onto the higher latitudes causing additional processing of materials in those regions. For example, the dark unknown material component closer to the poles could be either washed away by rain or processed by rain so that it is no longer detectable. In this scenario, the exposed old crust is expected to be rich in a material compatible with water ice (e.g., Griffith et al., 2003; McCord et al., 2006; Rodriguez et al., 2006; Soderblom, Tomasko, et al., 2007). Terrains closer to the equator are overlain and contaminated by the dark albedo dune material, probably wind-blown, and its spectral signature becomes similar to the darker undifferentiated plain regions like those in Caladan Planitia. This is consistent with the observed material transport directions as presented in Malaska et al. (2016). We then posit that the disappearance of the tholin-like materials at higher latitudes is due to their removal by pluvial or fluvial processes, leaving behind a material that is spectrally compatible with water ice and that is more resistant to rain. The origin of the materials covering the crater ejecta units and the alluvial fans remains the same as in our interpretation 1.

The current analysis cannot distinguish between these two plausible hypotheses (there could be more interpretations) or provide full compositional interpretations due to the limited spectral information available and the possible presence of more complex materials that the ones considered in this study. However, we show that Titan's surface composition, at the depths detected by VIMS, has significant latitudinal dependence even within the midlatitudes. The data that would lead to the full interpretation of the geological evolution of Titan are hidden in the secondary, tertiary, etc., constituents of the mixtures, and in better understanding of the origin and evolution processes.

\section{Acknowledgments}

All Cassini data used in this article can be accessed in the Planetary Data Systems (PDS). The spectral library databases can be accessed here: http:// ghosst.osug.fr. This research was supported by the Cassini Data Analysis and Participating Scientists Program (CDAPS) grant NH16ZDA001N to R.L. We also acknowledge the support from the French National Research Agency for the ANR project "CH4@Titan" (ref: BLAN08-2_321467). S. R. also acknowledges financial support from the UnivEarthS LabEx program of Sorbonne Paris Cite (ANR-10-LABX-0023 and ANR-11-IDEX-0005-02) and the French National Research Agency (ANRAPOSTIC-11-BS56-002 and ANR-12BS05-001-3/EXO-DUNES). This work was conducted at Jet Propulsion Laboratory (JPL) and the California Institute of Technology (Caltech) under contract with NASA. The authors would like to thank Thomas McCord and another anonymous reviewer for their very useful comments. @2017 California Institute of Technology. Government sponsorship acknowledged.

\section{References}

Atreya, S. K. (2010). The significance of trace constituents in the solar system. Faraday Discussions, 147, 9-29.

Barnes, J. W., Brown, R. H., Soderblom, L., Buratti, B. J., Sotin, C., Rodriguez, S., et al. (2007). Global-scale surface spectral variations on Titan seen from Cassini/VIMS. Icarus, 186, 242-258.

Barnes, J. W., Brown, R. H., Soderblom, L. A., Sotin, C., Le Mouélic, S., Rodriguez, S., et al. (2008). Spectroscopy, morphometry, and photoclinometry of Titan's dunefields from Cassini/VIMS. Icarus, 195, 400-414.

Barnes, J. W., Brown, R. H., Turtle, E. P., McEwen, A. S., Lorenz, R. D., Janssen, M., et al. (2005). A 5-micron-bright spot on Titan: Evidence for surface diversity. Science, 310, 92-95.

Bernard, J.-M., Quirico, E., Brissaud, O., Montagnac, G., Reynard, B., McMillan, B. P., et al. (2006). Reflectance spectra and chemical structure of Titan's tholins: Application to the analysis of Cassini Huygens observations. Icarus, 185, 301-307.

Bonnefoy, L. A., Hayes, A. G., Hayne, P. O., Malaska, M. J., Le Gall, A., Solomonidou, A., \& Lucas, A. (2016). Compositional and spatial variations in Titan dune and interdune regions from Cassini VIMS and RADAR. Icarus, 270, 222-237.

Boudon, V., Rey, M., \& Loete, M. (2006). The vibrational levels of methane obtained from analyses of high-resolution spectra. Journal of Quantitative Spectroscopy and Radiation Transfer, 98, 394-404.

Brassé, C., Munoz, O., Coll, P., \& Raulin, F. (2015). Optical constants of Titan aerosols and their tholins analogs: Experimental results and modeling/observational data. Planetary and Space Science, 109-110, 159-174.

Brown, R. H., Bellucci, G., Bibring, J.-P., Buratti, B. J., Capaccioni, F., Cerroni, P., et al. (2004). The Cassini Visual And Infrared Mapping Spectrometer (VIMS) Investigation. Space Science Reviews, 115, 111-168.

Campargue, A., Leshchishina, O., Wang, L., Mondelain, D., \& Kassi, S. (2013). The WKLMC empirical line lists $\left(5852-7919 \mathrm{~cm}^{-1}\right.$ ) for methane between $80 \mathrm{~K}$ and $296 \mathrm{~K}$ : "Final" lists for atmospheric and planetary applications. Journal of Molecular Spectroscopy, 291, 16-22.

Campargue, A., Wang, L., Mondelain, D., Kassi, S., Bézard, B., Lellouch, E., et al. (2012). An empirical line list for methane in the 1.26-1.71 $\mu$ m region for planetary investigations ( $T=80-300 \mathrm{~K}$ ). Application to Titan. Icarus, 219, 110-128.

Choukroun, M., \& Sotin, C. (2012). Is Titan's shape caused by its meteorology and carbon cycle? Geophysical Research Letters, 39, L04201. https://doi.org/10.1029/2011GL050747

Clark, R. N., Curchin, J. M., Barnes, J. W., Jaumann, R., Soderblom, L., Cruikshank, D. P., et al. (2010). Detection and mapping of hydrocarbon deposits on Titan. Journal of Geophysical Research, 115, E10005. https://doi.org/10.1029/2009JE003369

Coustenis, A., Lellouch, E., Maillard, J. P., \& McKay, C. P. (1995). Titan's surface: composition and variability from the newar-infrared albedo. Icarus, 118, 87-104.

de Bergh, C., Courtin, R., Bézard, B., Coustenis, A., Lellouch, E., Hirtzig, M., et al. (2012). Applications of a new set of methane line parameters to the modeling of Titan's spectrum in the $1.58 \mu \mathrm{m}$ window. Planetary and Space Science, 61, 85-98.

de Kok, R., Irwin, P., Teanby, N., Lellouch, E., Bézard, B., Vinatier, S., et al. (2007). Oxygen compounds in Titan's stratosphere observed by Cassini CIRS. Icarus, 186, 354-363.

Douté, S., \& Schmitt, B. (1998). A multi-layer bidirectional reflectance model for the analysis of planetary surface hyperspectral images at visible and near infrared wavelengths. Journal of Geophysical Research, 103, 31,367-31,390. https://doi.org/10.1029/98JE01894

Elachi, C., Allison, M. D., Borganelli, L., Encrenaz, P., Im, E., Janssen, M. A., et al. (2004). Radar: The Cassini Titan Radar Mapper. Space Science Reviews, 115, 71-110.

Evans, K. F. (2007). SHDOMPPDA: A radiative transfer model for cloudy sky data assimilation. Journal of the Atmospheric Sciences, 64, 3854-3864. 
Fulchignoni, M., Ferri, F., Angrilli, F., Ball, A. J., Bar-Nun, A., Barucci, M. A., et al. (2005). In situ measurements of the physical characteristics of Titan's environment. Nature, 438, 785-791.

Griffith, C. A., Owen, T., Geballe, T. R., Rayner, J., \& Rannou, P. (2003). Evidence for the exposure of water ice on Titan's surface. Science, 300, 628-630.

Grundy, W. M., \& Schmitt, B. (1998). The temperature-dependent near- infrared absorption spectrum of hexagonal $\mathrm{H}_{2} \mathrm{O}$ ice. Journal of Geophysical Research, 103, 25,809-25,822. https://doi.org/10.1029/98JE00738

Hartung, M., Herbst, T. M., Dumas, C., \& Coustenis, A. (2006). Limits to the abundance of surface $\mathrm{CO}_{2}$ ice on Titan. Journal of Geophysical Research, 111, E07S09. https://doi.org/10.1029/2005JE002642

Hirtzig, M., Bézard, B., Lellouch, E., Coustenis, A., de Bergh, C., Drossart, P., et al. (2013). Titan's surface and atmosphere from Cassini/VIMS data with updated methane opacity. Icarus, 226, 470-486.

Jacquinet-Husson, N., Crepeau, L., Armante, R., Boutammine, C., Chedin, A., Scott, N. A., et al. (2011). The 2009 edition of the GEISA spectroscopic database. Journal of Quantitative Spectroscopy and Radiation Transfer, 112, 2395-2445.

Janssen, M. A., Le Gall, A., Lopes, R. M., Lorenz, R. D., Malaska, M. J., Hayes, A. G., et al. (2016). Titan's surface at 2.18-cm wavelength imaged by the Cassini RADAR radiometer: Results and interpretations through the first ten years of observation. Icarus, 270, 443-459.

Janssen, M. A., Le Gall, A., \& Wye, L. C. (2011). Anomalous radar backscatter from Titan's surface? Icarus, 212, 321-328.

Janssen, M. A., Lorenz, R. D., West, R., Paganelli, F., Lopes, R., Kirk, R., et al. (2009). Titan's surface at 2.2-cm wavelength imaged by the Cassini RADAR radiometer: Calibration and first results. Icarus, 200, 222-239.

Jaumann, R., Kirk, R. L., Lorenz, R. D., Lopes, R. M. C., Stofan, E., Turtle, P. T., et al. (2009). Geology and Surface Processes on Titan. In Titan from Cassini-Huygens. Springer. Titan's surface at $2.18-\mathrm{cm}$ wavelength imaged by the Cassini RADAR radiometer: Results and interpretations through the first ten years of observation. Icarus, 270, 443-459.

Le Corre, L., Le Mouélic, S., Sotin, C., Barnes, J. W., Brown, R. H., Baines, K. H., et al. (2008). Global map of Titan's dune fields. In: European Planetary Science Congress. In Proceedings of the conference in Münster, Germany (667 pp.).

Le Gall, A., Janssen, M. A., Kirk, R. L., \& Lorenz, R. D. (2014). Modeling microwave backscatter and thermal emission from linear dune fields: Application to Titan. Icarus, 230, 198-207.

Le Gall, A., Janssen, M. A., Wye, L. C., Hayes, A. G., Radebaugh, J., Savage, C., et al. (2011). Cassini SAR, radiometry, scatterometry and altimetry observations of Titan's dune fields. Icarus, 213, 608-624.

Le Mouélic, S., Cornet, T., Rodriguez, S., Sotin, C., Barnes, J. W., Baines, K. H., et al. (2012). Global mapping of Titan's surface using an empirical processing method for the atmospheric and photometric correction of Cassini/VIMS images. Planetary and Space Science, 73, $178-190$.

Le Mouélic, S., Cornet, T., Rodriguez, S., Sotin, C., Barnes, J. W., Brown, R. H., et al. (2016). Producing Seamless Global Mosaics of Titan with the VIMS Imaging Spectrometer, 47th Lunar and Planetary Science Conference, LPI Contribution No. 1903, p. 2011.

Lellouch, E. (2006). Titan's zoo of clouds. Science, 311, 186-187.

Lopes, R. M. C., Kirk, R. L., Mitchell, K. L., LeGall, A., Barnes, J. W., Hayes, A., et al. (2013). Cryovolcanism on Titan: New results from Cassini RADAR and VIMS. Journal of Geophysical Research: Planets, 118, 416-435. https://doi.org/10.1002/jgre.20062

Lopes, R. M. . C., Malaska, M. J., Solomonidou, A., LeGall, A., Janssen, M. A., Neish, C., et al. (2016). Nature, distribution, and origin of Titan's undifferentiated plains ("Blandlands"). Icarus, 270, 162-182.

Lopes, R. M. C., Mitchell, K. L., Stofan, E. R., Lunine, J. I., Lorenz, R., Paganelli, F., et al. (2007). Cryovolcanic features on Titan's surface as revealed by the Cassini Titan Radar Mapper. Icarus, 186, 395-412.

Lopes, R. M. C., Stofan, E. R., Peckyno, R., Radebaugh, J., Mitchell, K. L., Mitri, G., et al. (2010). Distribution and interplay of geologic processes on Titan from Cassini radar data. Icarus, 205, 540-558.

Lorenz, R. D., Lopes, R. M., Paganelli, F., Lunine, J. I., Kirk, R. L., Soderblom, L. A., et al. (2008). Fluvial channels on Titan: Meteorological paradigm and Cassini RADAR observations. Planetary and Space Science, 56, 1132-1144.

Lorenz, R. D., Wood, C. A., Lunine, J. I., Wall, S. D., Lopes, R. M., Mitchell, K., et al. (2007). Titan's young surface: Initial impact crater survey by Cassini RADAR and model comparison. Geophysical Research Letters, 34, L07204. https://doi.org/10.1029/2006GL028971

Malaska, M., Radebaugh, J., Le Gall, A., Mitchell, K., Lopes, R., Wall, S. (2011). Evidence for an eroded upwarp near Sikun Labyrinthus, Titan. Lunar and Planetary Science Conference XLII, Abstract 1567.

Malaska, M. J., Lopes, R. M. C., Williams, D. A., Neish, C. D., Solomonidou, A., Soderblom, J. M., et al. (2016). Geomorphological map of the Afekan Crater region, Titan: Terrain relationships in the equatorial and mid-latitude regions. Icarus, 270, $130-161$.

Mastroguiseppe, M., Poggiali, V., Seu, R., Martufi, R., \& Notarnicola, C. (2014). Titan dune heights retrieval by using Cassini Radar Altimeter. Icarus, 230, 191-197.

McCord, T. B., Hansen, G. B., Buratti, B. J., Clark, R. N., Cruikshank, D. P., DÁversa, E., et al. (2006). Composition of Titan's surface from Cassini VIMS. Planetary and Space Science, 54, 1524-1539.

McCord, T. B., Hayne, P., Combe, J. -P., Hansen, G. B., Barnes, J. W., Rodriguez, S., et al. (2008). Titan's surface: Search for spectral diversity and composition using the Cassini VIMS investigation. Icarus, 194, 212-242.

Mitri, G., Showman, A. P., Lunine, J. I., \& Lorenz, R. D. (2007). Hydrocarbon lakes on Titan. Icarus, 186, 385-394.

Moore, J. M., Howard, A. D., \& Morgan, A. M. (2014). The landscape of Titan as witness to its climate evolution. Journal of Geophysical Research: Planets, 119, 2060-2077. https://doi.org/10.1002/2014JE004608

Mouélic, L., Paillou, P., Janssen, M. A., Barnes, J. W., Rodriguez, S., Sotin, C., et al. (2008). Mapping and interpretation of Sinlap crater on Titan using Cassini VIMS and RADAR data. Journal of Geophysical Research, 113, E04003. https://doi.org/10.1029/2007JE002965

Neish, C. D., Barnes, J. W., Sotin, C., MacKenzie, S., Soderblom, J. M., Le Mouélic, S., et al. (2015). Spectral properties of Titan's impact craters imply chemical weathering of its surface. Geophysical Research Letters, 42, 3746-3754. https://doi.org/10.1002/ 2015GL063824

Neish, C. D., Molaro, J. L., Lora, J. M., Howard, A. D., Kirk, R. L., Schenk, P., et al. (2016). Fluvial erosion as a mechanism for crater modification on Titan. Icarus, 270, 114-129.

Niemann, H. B., Atreya, S. K., Demick, J., Gautier, D., Haverman, J., Harpold, D., et al. (2010). Composition of Titan's lower atmosphere and simple surface volatiles as measured by the Cassini-Huygens probe gas chromatograph mass spectrometer experiment. Journal of Geophysical Research, 115, E12006. https://doi.org/10.1029/2010JE003659

Nikitin, A. V., Boudon, V., Wenger, C., Albert, S., Brown, L. R., Bauerecker, S., \& Quack, M. (2013). High resolution spectroscopy and the first global analysis of the Tetradecad region of methane 12CH4. Physical Chemistry Chemical Physics, 15, 10,071-10,093.

Radebaugh, J., Lorenz, R. D., Kirk, R. L., Lunine, J. I., Stofan, E. R., Lopes, R. M. C., et al. (2007). Mountains on Titan observed by Cassini radar. Icarus, 192, 77-91.

Radebaugh, J., Lorenz, R. D., Lunine, J. I., Wall, S. D., Boubin, G., Reffet, E., et al. (2008). Dunes on Titan observed by Cassini radar. Icarus, 194 690-703. 
Radebaugh, J., Ventra, D., Lorenz, R. D., Farr, T. G., Kirk, R. L., Hayes, A., et al. (2016). Alluvial and fluvial fans on Saturn's moon Titan reveal processes, materials and regional geology. In D. Ventra \& L. E. Clarke (Eds.), Geology and Geomorphology of Alluvial and Fluvial Fans: Terrestrial and Planetary Perspectives. Geological Society, London, Special Publications, 440. https://doi.org/10.1144/SP440.6

Rey, M., Nikitin, V., Bezard, B., Rannou, P., Coustenis, A., \& Tyuterev, V. (2018). New accurate theoretical line lists of ${ }^{12} \mathrm{CH}_{4}$ and ${ }^{13} \mathrm{CH}_{4}$ in the 0$13400 \mathrm{~cm}^{-1}$ range: Application to the modeling of methane absorption in Titan's atmosphere. Icarus, 303, 114-130.

Rodriguez, S., Garcia, A., Lucas, A., Appéré, T., Le Gall, A., Reffet, E., et al. (2014). Global mapping and characterization of Titan's dune fields with Cassini: Correlation between RADAR and VIMS observations. Icarus, 230, 168-179.

Rodriguez, S., Le Mouélic, S., Sotin, C., Clenet, H., Clark, R. N., Buratti, B., et al. (2006). Cassini/VIMS hyperspectral observations of the Huygens landing site on Titan. Planetary and Space Science, 54, 1510-1523.

Rothman, L. S., Gordon, I. E., Babikov, Y., Barbe, A., Chris Benner, D., Bernath, P. F., et al. (2013). The HITRAN2012 molecular spectroscopic database. Journal of Quantitative Spectroscopy and Radiation Transfer, 112, 2395-2445.

Schmitt, B., Quirico, E., Trotta, F., \& Grundy, W. (1998). Optical properties of ices from UV to infrared. In B. Schmitt, C. de Bergh, \& M. Festou (Eds.), Solar system ices, Astrophysics and Space Science Library (Vol. 227, pp. 199-240). Dordrecht: Kluwer Academic.

Schröder, S. E., \& Keller, H. U. (2008). The reflectance spectrum of Titan's surface at the Huygens landing site determined by the Descent Imager/Spectral Radiometer. Planetary and Space Science, 56, 753-769.

Singh, S., McCord, T. B., Combe, J.-P., Rodriguez, S., Cornet, T., Le Mouelic, S., et al. (2016). Acetylene on Titan's surface. The Astrophysical Journal, 828, 8 .

Soderblom, L. A., Kirk, R. L., Lunine, J. I., Anderson, J. A., Baines, K., Barnes, J., et al. (2007). Correlations between Cassini VIMS spectra and RADAR SAR images: Implications for Titan's surface composition and the character of the Huygens Probe Landing Site. Planetary and Space Science, 55, 2025-2036.

Soderblom, L. A., Tomasko, M. G., Archinal, B. A., Becker, T. L., Bushroe, M. W., Cook, D. A., et al. (2007). Topography and geomorphology of the Huygens landing site on Titan. Planetary and Space Science, 55, 2015-2024.

Sohl, F., Solomonidou, A., Wagner, F. W., Coustenis, A., Hussmann, H., \& Schulze-Makuch, D. (2014). Tidal stresses on Titan and implications for its geology and habitability. Journal of Geophysical Research: Planets, 119, 1013-1036. https://doi.org/10.1002/2013JE004512

Solomonidou, A., Coustenis, A., Hirtzig, M., Rodriguez, S., Stephan, K., Lopes, R. M. C., et al. (2016). Temporal variations of Titan's surface with Cassini/VIMS. Icarus, 270, 85-99.

Solomonidou, A., Hirtzig, M., Coustenis, A., Bratsolis, E., Le Mouélic, S., Rodriguez, S., et al. (2014). Surface albedo spectral properties of geologically interesting areas on Titan. Journal of Geophysical Research: Planets, 119, 1729-1747. https://doi.org/10.1002/2014JE004634

Sotin, C., Jaumann, R., Buratti, B. J., Brown, R. H., Clark, R. N., Soderblom, L. A., et al. (2005). Release of volatiles from a possible cryovolcano from near-infrared imaging of Titan. Nature, 435, 786-789.

Tobie, G., Lunine, J. I., \& Sotin, C. (2006). Episodic outgassing as the origin of atmospheric methane on Titan. Nature, 440, 61-64.

Tomasko, M. G., Archinal, B., Becker, T., Bézard, B., Bushroe, M., Combes, M., et al. (2005). Rain, winds and haze during the Huygens probe's descent to Titan's surface. Nature, 438, 765-778.

Tomasko, M. G., Doose, L., Engel, S., Dafoe, L. E., West, R., Lemmon, M., et al. (2008). A model of Titan's aerosols based on measurements made inside the atmosphere. Planetary and Space Science, 56, 669-707.

Trotta, F., \& Schmitt, B. (1996). Determination of the optical constants of solids in the mid infrared. In J. M. Greenberg (Ed.), The Cosmic Dust Connection, NATO ASI Series C (Vol. 487, pp. 179-184). Dordrecht: Springer, Kluwer Academic.

Williams, D. A., Radebaugh, J., Lopes, R. M. C., \& Stofan, E. (2011). Geomorphologic mapping of the Menrva region of Titan using Cassini RADAR data. Icarus, 212, 744-750.

Wood, C. A., Lorenz, R., Kirk, R., Lopes, R., Mitchell, K., Stofan, E., \& The Cassini RADAR Team (2010). Impact craters on Titan. Icarus, 206, 334-344. 